\title{
Advances in the pathophysiology and treatment of relapsed/refractory Hodgkin's lymphoma with an emphasis on targeted therapies and transplantation strategies
}

\author{
This article was published in the following Dove Press journal: \\ Blood and Lymphatic Cancer:Targets and Therapy \\ 9 May 2017 \\ Number of times this article has been viewed
}

\author{
Theodoros Karantanos' \\ loannis Politikos ${ }^{2}$ \\ Vassiliki A Boussiotis ${ }^{3-5}$ \\ 'General Internal Medicine Section, \\ Boston Medical Center, Boston \\ University School of Medicine, Boston, \\ MA, ${ }^{2}$ Adult Bone Marrow Transplant \\ Service, Department of Medicine, \\ Memorial Sloan Kettering Cancer \\ Center, New York, NY, ${ }^{3}$ Division of \\ Hematology-Oncology, ${ }^{4}$ Department \\ of Medicine, Beth Israel Deaconess \\ Medical Center, ${ }^{5}$ Beth Israel \\ Deaconess Cancer Center, Harvard \\ Medical School, Boston, MA, USA
}

\begin{abstract}
Hodgkin's lymphoma (HL) is highly curable with first-line therapy. However, a minority of patients present with refractory disease or experience relapse after completion of frontline treatment. These patients are treated with salvage chemotherapy followed by autologous stem cell transplantation (ASCT), which remains the standard of care with curative potential for refractory or relapsed HL. Nevertheless, a significant percentage of such patients will progress after ASCT, and allogeneic hematopoietic stem cell transplantation remains the only curative approach in that setting. Recent advances in the pathophysiology of refractory or relapsed HL have provided the rationale for the development of novel targeted therapies with potent anti-HL activity and favorable toxicity profile, in contrast to cytotoxic chemotherapy. Brentuximab vedotin and programmed cell death-1-based immunotherapy have proven efficacy in the management of refractory or relapsed HL, whereas several other agents have shown promise in early clinical trials. Several of these agents are being incorporated with transplantation strategies in order to improve the outcomes of refractory or relapsed HL. In this review we summarize the current knowledge regarding the mechanisms responsible for the development of refractory/relapsed HL and the outcomes with current treatment strategies, with an emphasis on targeted therapies and hematopoietic stem cell transplantation.
\end{abstract}

Keywords: relapsed/refractory Hodgkin's lymphoma, pathophysiology, novel agents, immunotherapy, hematopoietic stem cell transplantation

\section{Introduction}

Hodgkin's lymphoma (HL) is the most common malignancy in adolescents and young adults. ${ }^{1} \mathrm{HL}$ is divided into classical HL (cHL) accounting for $95 \%$ of cases and nodular lymphocyte-predominant HL, which is less common. The cHL subtype is defined by the presence of neoplastic cells of B-cell origin expressing CD30 and CD45, including mononucleated Hodgkin cells and multinucleated Reed-Sternberg (RS) cells, which are in direct interaction with an inflammatory microenvironment consisting of granulocytes, mast cells, $\mathrm{T}$ and B lymphocytes, plasma cells and fibroblasts. ${ }^{2}$ The cross talk between cancer cells and microenvironment is critical for the pathogenesis and progression of HL. ${ }^{3,4}$

First-line chemotherapy and/or radiation for $\mathrm{cHL}$ in patients with advanced disease is associated with cure rates between $70 \%$ and $75 \%{ }^{5,6}$ However, $25 \%-30 \%$ of patients either have primary refractory disease or will relapse following first-line therapy. ${ }^{7}$ Salvage chemotherapy followed by autologous stem cell transplantation (ASCT) is
Correspondence: Vassiliki A Boussiotis Beth Israel Deaconess Cancer Center, 330 Brookline Avenue, Dana 513-5 I7, Boston, MA 02215, USA

Tel + I 6176678563

Email vboussio@bidmc.harvard.edu 
the standard of care for these patient groups. However, only a subset of patients with primary refractory or relapsed HL achieves long-term progression-free survival (PFS) with this approach, and the prognosis is influenced by the presence or absence of certain risk factors. ${ }^{8,9}$ Patients who progress or relapse after ASCT have poor prognosis with a median survival of 12-29 months. ${ }^{10,11}$ Thus, development of novel therapeutic approaches is critical for the treatment of relapsed or refractory HL. The antibody-drug immunoconjugate targeting CD30, named brentuximab vedotin, and immunotherapies targeting programmed cell death-1 (PD-1) receptor represent the most promising new therapies, ${ }^{12,13}$ while several promising agents are in development or in early clinical trials. However, to date, allogeneic hematopoietic stem cell transplantation (alloHCT) remains the only potentially curative approach for relapsed or recurred disease. ${ }^{14}$

The purpose of this review is to summarize recent data regarding the molecular mechanisms implicated in the development of refractory or relapsed HL and novel therapeutic approaches for the management of patients failing frontline therapy.

\section{Mechanisms involved in the development of refractory and relapsed HL}

\section{The role of microenvironment}

In contrast to most other neoplastic diseases, the nonneoplastic cells of the tumor microenvironment outnumber the neoplastic cells in HL, and the distribution of these cells may contribute to the emergence of resistance to conventional therapy. ${ }^{15,16}$

\section{Macrophages}

Infiltration of the cHL microenvironment by $\mathrm{CD}^{+} 8^{+}$macrophages is considered a negative predictor of PFS for $\mathrm{cHL}$ after induction with doxorubicin, bleomycin, vinblastine, dacarbazine (ABVD) treatment with or without radiotherapy, independent of the International Prognostic Score. ${ }^{17}$ High numbers of $\mathrm{CD}^{+} 8^{+}$and $\mathrm{CD} 163^{+}$macrophages in $\mathrm{cHL}$ are associated with worse overall survival (OS), but they also correlate with the presence of Epstein-Barr virus (EBV) in the neoplastic cells ${ }^{18}$ which, in turn, has been associated with worse outcomes mainly in older individuals. ${ }^{19,20}$ The exact mechanism underlying the negative impact of macrophages on the above-described outcomes has not been fully elucidated, but it is believed that these cells have an immunosuppressive role and, therefore, may hamper the antitumor immune responses (Figure 1). In support of this hypothesis, macrophages in the tumor microenvironment can inhibit the response of $T$ cells by releasing various immunosuppressive cytokines, such as IL-10 and TGF- $\beta .{ }^{21}$ Moreover, TNF- $\alpha$ and IL-10 secretion from monocytes induces the expression of PD-L1 by the same cells in an autocrine manner, leading to decreased T-cell activity and proliferation. ${ }^{22}$ Tumor-associated macrophages are also known to secrete CCL22, which promotes the trafficking of regulatory $\mathrm{T}$ (Treg) cells in the tumor microenvironments through the activation of CCL22/CCR4 axis. ${ }^{23}$ In turn, Treg cells inhibit antitumor T-cell responses, further supporting the immunosuppressive role of macrophages in the microenvironment of cHL.

\section{T cells}

The presence of Treg and $\mathrm{CD}^{+}{ }^{+} \mathrm{T}$ cells, especially with Th2 phenotype, in the tumor microenvironment has been associated with worse prognosis likely through immune escape. ${ }^{24}$ Higher density of Treg cells and decreased density of cytotoxic T cells correlate with poorer PFS and OS in patients with $\mathrm{cHL} .{ }^{25}$ Moreover, higher CD4/CD8 ratio in the tumor microenvironment is an independent factor for ABVD treatment failure in patients with HL. ${ }^{26}$

\section{Interactions between $\mathrm{HL}$ and cells of the microenvironment}

The interactions between the neoplastic cells and the cells of the microenvironment play a critical role in the development of refractory or relapsed HL. RS cells produce various Th2 and Treg cell chemoattractive cytokines such as IL-4, IL-5 and IL-1027,28; CCL22 and CCL5 ${ }^{29}$ and also cytokines with macrophage chemotactic activity, such as IL-5 and IL-8. ${ }^{30}$ The recruitment of these cells is reinforced by the reactive cells themselves and particularly macrophages secreting CCL-3, CCL-4 and CCL-8. ${ }^{31,32}$ Similarly, the neoplastic cells secrete TNF- $\alpha$ and TGF- $\beta$ promoting the activation of fibroblasts. ${ }^{33,34}$ In turn, collagen IV produced by fibroblasts in the tumor microenvironment is recognized by the DDR 1 receptor in $\mathrm{RS}$ cells, ${ }^{35}$ which is a tyrosine kinase promoting the survival and proliferation of these cells. ${ }^{36}$ These mechanisms generate a vicious cycle between the neoplastic cells and particular components of the microenvironment, promoting resistance to treatment and disease progression. The inflammatory cells of the tumor microenvironment express surface antigens that act as survival signals for the neoplastic cells. These include CD40L expressed on T cells and CD30L expressed on masts cells, and bind the CD40 and CD30 receptors, respectively, which are expressed on RS and Hodgkin cells (Figure 1). ${ }^{30,37}$ CD40L:CD40 signaling leads to increased survival 


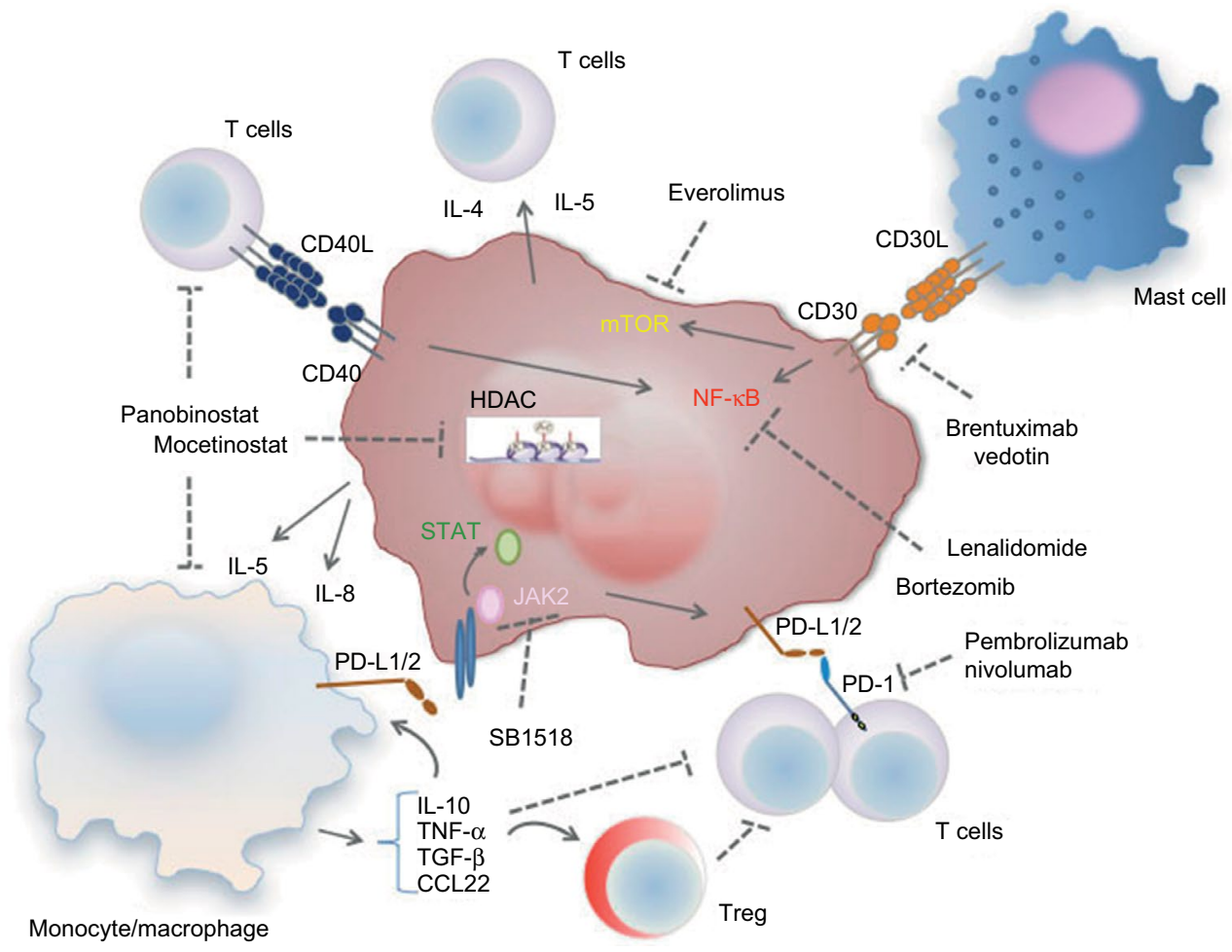

Figure I Dysregulation of the TME involved in the development of refractory/relapsed $\mathrm{HL}$ and targets of novel compounds targeting the TME or the malignant cells. Notes: In HL, macrophages release TNF- $\alpha$ and IL- 10 that induce the expression of PD-LI/2 by monocytes and malignant cells in an autocrine manner leading to decreased T-cell activity and antitumor function. PD-LI/2 are also increased in neoplastic cells through gene amplification with simultaneous increase of JAK2 and activation of JAK-STAT signaling. Tumor-associated macrophages also produce T-cell immunosuppressive cytokines IL-I0 and TGF- $\beta$, as well as CCL22, which promote the recruitment of Treg cells in the tumor microenvironment through the activation of CCL22/CCR4 axis, thereby further inhibiting anti-tumor T-cell responses. Novel therapies target signaling pathways that promote the expression of inhibitory receptors, recruit Treg cells and suppress T-cell immune function. CD30 expressed on malignant cells is a novel therapeutic target. Abbreviations: HL, Hodgkin's lymphoma; Treg, regulatory T; PD-LI/2, programmed cell death-LI/2; mTOR, mammalian target of rapamycin; TME, tumor microenvironment; HDAC, histone deacetylases.

of Hodgkin cells and disease progression. ${ }^{38}$ CD40 ligation inhibits Fas-mediated apoptosis of Hodgkin cells potentially promoting the development of resistant disease. ${ }^{39} \mathrm{CD} 40$ also promotes the upregulation of IRF4/MUM1 expression through the activation of NF- $\mathrm{KB} \cdot{ }^{40,41}$ Addition of SCD40L in cultures of Hodgkin cells protects them from the apoptotic effect of bortezomib by downregulating IRF $4,{ }^{42}$ which acts as a survival factor. CD40-mediated activation can promote the survival and growth of Hodgkin and RS cells via ERK phosphorylation and might be involved in the contact and interaction of the malignant cells with activated cytokineproducing $\mathrm{CD}^{+} \mathrm{T}$ cells in the tumor microenvironment creating a positive feedback loop that leads to Hodgkin and RS cell expansion. ${ }^{43,44}$ Similarly, CD30L expressed on mast cells of the tumor microenvironment interacts with CD30 on the surface of RS cells and leads to activation of NF- $\mathrm{\kappa B}$ signaling, resulting in increased cell survival, proliferation ${ }^{45}$ and secretion of cytokines including IL- 6 and TNF- $\alpha{ }^{46}$

These signaling events and secreted factors have a significant effect in the cellular composition of the tumor microenvironment and the development of refractory and relapsed HL.

\section{Aberrant activation of signaling pathways in $\mathrm{HL}$ cells}

Several oncogenic pathways have been implicated in the development of disease resistance and progression. As mentioned earlier, aberrant activation of NF- $\mathrm{KB}$ is a hallmark of HL cell lines ${ }^{47}$ as well as primary RS and Hodgkin cells. ${ }^{48}$ Activation of IKK via upregulation of TRAF is one of the main mechanisms implicated in the activation of NF- $\kappa B$ in HL. ${ }^{49}$ Oligomerization of CD30 molecules recruits TRAFs leading to IKK activation and subsequent NF- $\mathrm{KB}$ upregulation. ${ }^{50}$ Gain-of-function mutations in positive regulators of $\mathrm{NF}-\mathrm{KB}$ such as BCL3 and inactivating mutations of its negative regulators such as TNFAIP and NFKBIA have been identified with high frequency in $\mathrm{HL} .{ }^{24}$ Activation of NF- $\kappa \mathrm{B}$ in $\mathrm{HL}$ promotes cell cycle progression by upregulation of cyclins $\mathrm{D} 1$ and $\mathrm{D} 2,{ }^{51} \mathrm{c}-m y c^{52}$ and $\mathrm{c}-m y b,{ }^{53}$ and inhibits apoptosis by induction of antiapoptotic molecules such as BCL- $\mathrm{X}_{\mathrm{L}}{ }^{54}$ and c-FLIP. ${ }^{55} \mathrm{NF}-\mathrm{\kappa B}$ also promotes secretion of various cytokines such as CCL5, CCL7 and IL-6 by Hodgkin cells, which not only act as autocrine promoters of cancer cell proliferation but also alter the tumor microenvironment by regulating the trafficking of macrophages. ${ }^{24}$ 
PI3K pathway signaling alterations have been identified in HL, and the efficacy of PI3K, Akt and mTOR inhibitors in HL is currently under evaluation. INPP5, a PI3K inhibitor, is silenced in HL cells, ${ }^{56} \mathrm{PI} 3 \mathrm{~K}$ activation has been implicated in the development of resistance to brentuximab vedotin, while inhibition of PI3K by TGR-1202 increases the efficacy of the drug by promoting mitotic arrest. ${ }^{57}$ STAT proteins are activated in RS and Hodgkin cells. ${ }^{58}$ and are essential for their survival and proliferation. ${ }^{59,60}$ Moreover, JAK2 rearrangements leading to constitutive JAK2 activation and STAT signaling are recurrent in $\mathrm{cHL},{ }^{61}$ while inhibitors of this pathway, such as lestaurtinib, induce apoptosis in HL cell lines. ${ }^{62}$ Nonsense, missense and frameshift mutations of PTPN1, a negative regulator of JAK-STAT signaling, are observed in a high percentage of HL cell lines and HL cases, ${ }^{63}$ while HSP90 is critical for the activation of JAK-STAT signaling in HL cells. ${ }^{64}$ Importantly, selective amplification of the 9p24.1 chromosome region is associated with simultaneous amplification of PD-L1 and JAK2. As a consequence, the enhanced JAK-STAT signaling further promotes the expression of PD-L1 and PD-L2 in Hodgkin cells, ${ }^{65}$ thereby inhibiting T-cell activation and antitumor immunity. Coexpression of PD-L1 and PD-1 in the HL microenvironment serves as an independent poor prognostic factor, ${ }^{66}$ while a subgroup analysis demonstrated that the prognostic value of PD-1 is significant for patients with limited-stage cHL. ${ }^{67}$

\section{EBV infection}

Monoclonal EBV infection occurs in $40 \%$ of $\mathrm{cHL}$ and up to $90 \%$ of HIV-related HLs suggesting that EBV may be impli- cated in oncogenic signaling. Indeed, EBV-infected HL cells overexpress LMP1, which leads to constitutive activation of TNF- $\alpha$ receptor, NF- $\kappa \mathrm{B}$ signaling and protection from apoptosis. ${ }^{68}$ The absence of mutations of $\mathrm{I} \kappa \mathrm{B} \alpha$, a suppressor of NF- $\kappa B$ activation, in EBV-positive HL cells suggests that EBV activates an alternate (non-I $\kappa \mathrm{B} \alpha$-dependent) mechanism of NF- $\kappa \mathrm{B}$ activation. ${ }^{69}$ EBV-infected HL cells overexpress LMP2 which induces the upregulation of E2F, EBF and Pax-5, promoting cell survival and proliferation. ${ }^{70}$ Despite the confirmed overexpression of oncogenes encoded in the EBV genome in Hodgkin and RS cells, studies regarding the impact of EBV infection on prognosis and response to treatment are inconclusive.

\section{Novel therapeutic approaches for primary refractory and early relapsed $\mathbf{H L}$}

Advancements in the understanding of HL pathophysiology have led to the development of novel therapeutic approaches for the management of relapsed or refractory disease. Compounds that have been evaluated in clinical trials for this purpose include agents targeting the oncogenic signaling in the neoplastic cells or the tumor microenvironment (Table 1).

\section{Targeting the malignant cells}

Multiple oncogenic pathways are upregulated in HL cells, including CD30 downstream signaling pathways, JAKSTAT and PI3K-Akt-mTOR. Compounds individually targeting these signaling pathways as single agents or as part of

Table I Novel agents for relapsed/refractory HL

\begin{tabular}{|c|c|c|c|c|}
\hline Agent & Target & Line of therapy & Results & Reference \\
\hline \multirow[t]{4}{*}{ Brentuximab vedotin } & CD30 & Refractory/relapsed HL & OR $50 \%$ with a median duration of 10 months & 12 \\
\hline & & Relapsed/refractory HL after ASCT & ORR $75 \%$, CR $35 \%$ & 72 \\
\hline & & $\begin{array}{l}\text { Relapsed/refractory HL after ASCT or } \\
\text { unable to do ASCT }\end{array}$ & $\begin{array}{l}\text { Brentuximab vedotin before AlloSCT } \\
\text { improved PFS }\end{array}$ & 73 \\
\hline & & Relapsed/refractory HL after ASCT & OR 50\%, CR 38\%, median PFS 7.8 months & 77 \\
\hline \multirow[t]{2}{*}{ Nivolumab } & PD-I & Relapsed/refractory HL & OR $87 \%$, CR I7\%, PR 70\% & 13 \\
\hline & & Relapsed/refractory HL after ASCT & OR $66.3 \%$ & 90 \\
\hline Pembrolizumab & PD-I & Relapsed/refractory $\mathrm{HL}$ after ASCT & PR $48 \%$, OR $65 \%$ & 91 \\
\hline Mocetinostat & HDAC & Relapsed/refractory HL & Disease control rate $35 \%$ & 95 \\
\hline Panobinostat & HDAC & Relapsed/refractory $\mathrm{HL}$ after ASCT & OR $27 \%$, PR $23 \%$, CR $4 \%$ & 96 \\
\hline Bortezomib & $N F-\kappa B$ & Relapsed/refractory HL & No response & 84 \\
\hline \multirow[t]{2}{*}{ Lenalidomide } & NF- $\mathrm{KB}$ & $\begin{array}{l}\text { Relapsed/refractory HL ( } 87 \% \text { with prior } \\
\text { ASCT) }\end{array}$ & PR $16 \%$, stable disease $14 \%$ & 88 \\
\hline & & $\begin{array}{l}\text { Relapsed/refractory HL after ASCT in } \\
\text { combination with cyclophosphamide }\end{array}$ & ORR $38 \%$, clinical benefit $62 \%$ & 89 \\
\hline SBI518 & JAK2 & Relapsed/refractory HL & CR I $2 \%$, PR $44 \%$ & 78 \\
\hline Everolimus & mTOR & $\begin{array}{l}\text { Relapsed/refractory HL ( } 84 \% \text { with prior } \\
\text { ASCT) }\end{array}$ & ORR $47 \%$, PR $42 \%$, CR $5 \%$ & 79 \\
\hline
\end{tabular}

Abbreviations: ASCT, autologous stem cell transplantation; CR, complete response; HL, Hodgkin's lymphoma; OR, overall response; ORR, overall response rate; PFS, progression-free survival; PR, partial response. 
combinational approaches have generated promising results, especially in patients with refractory or relapsed disease.

Brentuximab vedotin, an antibody-drug immunoconjugate targeting CD30, has demonstrated high efficacy in cHL. ${ }^{71}$ In a Phase I trial including 45 patients with refractory or relapsed HL, the objective response at the maximum tolerated dose was $50 \%$ with a median duration of 10 months, whereas $86 \%$ of evaluable patients had some disease regression. ${ }^{12}$ In a subsequent Phase II clinical trial in patients with relapsed and refractory HL after ASCT, the objective response rate was $75 \%$. Approximately one-third of patients achieved complete response (CR) with a median duration of 20.5 months. ${ }^{72}$ Moreover, brentuximab vedotin has been used, as a single agent or in combination, as salvage chemotherapy prior to ASCT with low toxicity and promising efficacy. ${ }^{73-75}$ Similarly, the administration of brentuximab vedotin before alloHCT has been associated with improved 2-year PFS and OS and decreased relapsed rate. ${ }^{76}$ This is particularly critical for the improvement of outcomes in patients who progress after ASCT and proceed to alloHCT. Administration of brentuximab vedotin after failure of alloHCT was associated with an overall response (OR) rate of $50 \%$ and a $\mathrm{CR}$ rate of $38 \%$ without any differences in the rates of graft versus host disease (GVHD) and cytomegalovirus (CMV) reactivation. ${ }^{77}$ Together, these data strongly suggest that brentuximab vedotin is a promising therapeutic modality for patients with relapsed and refractory HL before or after failure of ASCT. Moreover, administration of brentuximab vedotin before alloHCT may improve transplant outcomes.

The efficacy of a novel JAK2 inhibitor, SB1518, was evaluated in 34 patients with relapsed or refractory HL or non-HL demonstrating CR in 4 patients and partial response (PR) in 15 patients. $^{78}$ The mTOR inhibitor everolimus as single agent is associated with an OR rate of $47 \%$ and $P R$ in $42 \%$ of patients. ${ }^{79}$ These clinical outcomes strongly support the conclusion that therapeutic targeting of oncogenic pathways in HL cells represents a promising treatment approach in patients with relapsed or refractory disease. Moreover, the combination of such targeted therapies with chemotherapy during early stages of disease warrants further investigation.

It should be noted that not all molecular/immunological aberrations of HL neoplastic cells are amenable to targeted therapies. Although some RS cells - as well as infiltrating lymphocytes - express CD20, the use of the anti-CD20 monoclonal antibody rituximab in combination with chemotherapy has not provided clinical benefit for the treatment of cHL. ${ }^{80,81}$ Similarly, CD80, which is expressed on RS cells and immune cells in the tumor microenvironment, has also been used as a therapeutic target, but the anti-CD80 monoclonal antibody galiximab did not provide a significant benefit. ${ }^{82}$

\section{Targeting cellular components of the tumor microenvironment}

Given the critical role of the cross talk between the neoplastic cells and the cellular components of the tumor microenvironment, compounds targeting these interactions have shown significant efficacy in HL (Figure 1).

The efficacy of bortezomib and lenalidomide has been evaluated in patients with advanced HL with a goal to target $\mathrm{NF}-\kappa \mathrm{B}$, which is activated by the interactions of cancer cells with components of the tumor microenvironment, as previously discussed. Bortezomib as single agent, or in combination with dexamethasone or gemcitabine, has not shown any significant activity in patients with relapsed or refractory disease, ${ }^{83-85}$ whereas addition of bortezomib to ifosfamidebased combination regimens led to more encouraging results. ${ }^{86,87}$ In a Phase II clinical trial, lenalidomide as single agent led to an OR of $19 \%$ and a cytostatic OR rate of $33 \%$ in heavily pretreated patients with cHL. ${ }^{88}$ In another study including 46 patients with refractory or relapsed HL after ASCT, lenalidomide in combination with metronomic lowdose cyclophosphamide was associated with an OR rate of $38 \%$, whereas $62 \%$ of the patients achieved clinical benefit. ${ }^{89}$ These conclusions support a beneficial role of lenalidomide potentially in combination with chemotherapy in patients with refractory or relapsed HL. It should be noted, however, that the mechanisms accounting for the antilymphoma effect of lenalidomide in HL have not been fully elucidated and may extend beyond the interference with the NF- $\kappa$ B pathway.

Various clinical studies provide compelling evidence that targeting the PD-1/PD-L1 pathway is a promising approach for patients with relapsed or refractory HL. Specifically, a recent Phase I clinical trial demonstrated that the PD-1 blocking antibody, nivolumab, has a good toxicity profile. Adverse events of any grade and those of grade 3 occured in $78 \%$ and $22 \%$ of patients, respectively. ${ }^{13}$ In this study, objective responses were observed in 20 of 23 patients (87\%), although CR was not common (17\%). ${ }^{13}$ Subsequently, a single-arm Phase II clinical trial evaluating the efficacy of nivolumab in patients with HL after failure of ASCT and brentuximab vedotin reported OR in $66.3 \%$ of patients..$^{90}$ Pembrolizumab, a different PD-1 blocking antibody, was recently shown to induce PR in $48 \%$ of patients with HL relapsing after ASCT with objective responses in the order of $65 \% .{ }^{91}$ Pembrolizumab was also associated with objective responses in $80 \%$ of patients with relapsed/refractory HL who failed previous 
treatment with brentuximab vedotin. Thus, targeting PD-1/ PD-L1 interaction in the tumor microenvironment is a promising therapeutic approach for patients with relapsed and refractory $\mathrm{HL}$.

HDACs are commonly overexpressed or overactivated in neoplastic diseases, and targeting of HDACs has been employed as a novel therapeutic approach in various malignancies including lymphomas. ${ }^{92}$ In HL, activation of HDACs has been associated with downregulation of B-cell-specific antigens and p21, upregulation of STAT signaling and suppression of caspase pathways. ${ }^{93}$ In addition, tumor-infiltrating lymphocytes in cHL express high levels of HDACs,,${ }^{94}$ suggesting that HDAC inhibitors might target not only neoplastic cells but also immune cells of the tumor microenvironment. Recent Phase II clinical trials have demonstrated significant efficacy of HDAC inhibitors in patients with relapsed ${ }^{95}$ and recurrent HL following ASCT. ${ }^{96}$ The HDAC inhibitor panobinostat alters the secretion of cytokines including TNF- $\alpha$ and IFN- $\gamma$, thus modulating the activity of lymphocytes in the tumor microenvironment and promoting cancer cell autophagy and death. ${ }^{97}$ These panobinostat-mediated cytokine modulations have been recently associated with alterations in PD-1 expression in T cells, ${ }^{98}$ suggesting that the combination of HDAC inhibitors and PD-1/PD-L1 inhibitors might be a promising therapeutic approach in HL. Other studies have focused on the combination of HDAC inhibitors with molecules targeting oncogenic signaling in HL including mTOR inhibitors, such as everolimus and sirolimus, ${ }^{99,100}$ or angiogenesis inhibitors, such as sorafenib. ${ }^{101}$

\section{Transplantation strategies for refractory or relapsed $\mathrm{HL}$}

Outcomes of refractory or relapsed HL treated with conventional dose salvage chemotherapy were historically characterized by transient responses and low probability for long-term remission or cure. ${ }^{102}$ Although the development of novel targeted therapies with potent activity against HL is promising, long-term outcomes with these agents are not well established. The role of ASCT in refractory and relapsed HL is well established and ASCT remains the standard of care for patients who are candidates for curative therapy. AlloHCT is typically reserved for carefully selected patients who relapse after ASCT. Moreover, several transplantation strategies in the autologous or allogeneic setting have been developed with the goal to further improve outcomes, albeit with variable success (Table 2).

Table 2 Transplantation strategies for relapsed/refractory $\mathrm{HL}$

\begin{tabular}{|c|c|}
\hline Transplantation strategies & References \\
\hline $\begin{array}{l}\text { ASCT following high-dose chemotherapy is associated with PFS advantage over nontransplant strategies and is considered the } \\
\text { standard of care in patients with relapsed or refractory HL who are responding to salvage therapy. }\end{array}$ & $8,103-108,135-138$ \\
\hline $\begin{array}{l}\text { A variety of pre-ASCT salvage regimens can be considered and are associated with ORR in approximately two-thirds of patients } \\
\text { and CR in approximately one-third of patients. Common regimens include ICE, ESHAP, DHAP, GV, GDV, and more recently BV in } \\
\text { sequence or in combination with cytotoxic chemotherapy or PD-I inhibitors. There is not enough evidence that one regimen is } \\
\text { superior to others. }\end{array}$ & $8,13,73-75,1|I|-120$ \\
\hline $\begin{array}{l}\text { A variety of myeloablative conditioning regimens are considered acceptable for patients with relapsed or refractory } \mathrm{HL} \\
\text { undergoing ASCT, most commonly BEAM, CBV, busulfan-based or TBI-based regimens. BEAM may be superior to other } \\
\text { conditioning regimens for } \mathrm{HL} \text { based on retrospective registry data. }\end{array}$ & $\begin{array}{l}8,106,107,113 \\
121-134\end{array}$ \\
\hline Pre-ASCT FDG-PET is a major determinant of post-ASCT relapse risk and may be used for risk-adapted treatment design. & $74,113,14|| 48-152$, \\
\hline Frontline ASCT as consolidation for high-risk $\mathrm{HL}$ is not associated with a survival benefit. & $154-156$ \\
\hline SHDCT is associated with increased toxicity and no survival benefit in patients with relapsed ASCT. & 163 \\
\hline $\begin{array}{l}\text { Tandem ASCT may be of some benefit to chemoresistant patients with relapsed or refractory HL, but routine use has not been } \\
\text { adopted due to lack of randomized data. }\end{array}$ & $164-168$ \\
\hline $\begin{array}{l}\text { BV maintenance post-ASCT is associated with PFS benefit in patients with relapsed or refractory } \mathrm{HL} \text { undergoing } \mathrm{HL} \text { with one or } \\
\text { more high-risk factors. }\end{array}$ & 142 \\
\hline Second ASCT may be considered in patients with long remission duration after first ASCT, but data are limited. & 172 \\
\hline $\begin{array}{l}\text { alloHCT should be offered to patients who relapse post-ASCT, who are not considered curable with standard chemotherapy, } \\
\text { and is associated with long-term disease control in a minority of patients. }\end{array}$ & $\begin{array}{l}173,174,177-182 \\
187,191-199\end{array}$ \\
\hline $\begin{array}{l}\text { RIC alloHCT is associated with less TRM and is considered the standard of care, although there is no consensus regarding the } \\
\text { optimal conditioning regimen and intensity. }\end{array}$ & $\begin{array}{l}175-177,180 \\
184,199\end{array}$ \\
\hline $\begin{array}{l}\text { Alternative graft sources (UCBT, haploidentical) are acceptable in patients who lack suitable HLA-matched related or unrelated } \\
\text { donors. }\end{array}$ & $191-198$ \\
\hline
\end{tabular}

Abbreviations: alloHCT, allogeneic hematopoietic stem cell transplantation; ASCT, autologous stem cell transplantation; BV, brentuximab vedotin; BEAM, carmustine (BCNU), etoposide, cytarabine (Ara-C) and melphalan; $\mathrm{CBV}$, cyclophosphamide, carmustine and etoposide; CR, complete response; DHAP, dexamethasone, cisplatin and cytarabine; ESHAP, etoposide, methylprednisolone, cytarabine and cisplatin; GV, gemcitabine and vinorelbine; GVD, GV with doxorubicin; HL, Hodgkin's lymphoma; ICE, ifosfamide, carboplatin and etoposide; ORR, overall response rate; PFS, progression-free survival; RIC, reduced intensity conditioning; SHDCT, sequential high-dose chemotherapy; TRM, treatment-related mortality; UCBT, umbilical cord blood transplantation. 


\section{Autologous transplantation (ASCT)}

Early experience with the use of high-dose chemotherapy requiring autologous stem cell support for the treatment of relapsed or refractory HL showed promising results. ${ }^{103-105}$ The British National Lymphoma Investigation compared in a randomized fashion the outcomes of patients with $\mathrm{HL}$ relapsing after first-line chemotherapy who were treated either with non-myeloablative doses of carmustine (BCNU), etoposide, cytarabine (Ara-C) and melphalan (mini-BEAM) administered without stem cell support, or with high-dose BEAM conditioning followed by ASCT T. ${ }^{106}$ Event-free survival (EFS) and PFS were significantly improved in the arm treated with BEAM plus ASCT. Similarly, in a study by the German Hodgkin Study Group, 161 patients with relapsed HL were treated with two cycles of non-myeloablative doses of dexamethasone and BEAM (Dexa-BEAM), and the responders were subsequently randomized to two more cycles of either Dexa-BEAM or BEAM followed by ASCT. ${ }^{107}$ Freedom from treatment failure (FFTF) at 3 years was significantly improved in chemosensitive patients who underwent ASCT compared to those who received conventional chemotherapy, although no significant OS benefit was shown. In both studies, radiotherapy was allowed for patients with residual sites of disease. A systematic review and meta-analysis of these two randomized studies again demonstrated that ASCT was associated with improved PFS (hazard ratio [HR] $=0.55 ; 95 \%$ confidence interval [CI]: $0.35-0.86 ; p=0.009)$, but only a trend toward improved OS (HR $=0.67 ; 95 \%$ CI: $0.41-1.07 ; p=0.10),{ }^{108}$ most likely due to lack of statistical power. Based on the results of these two randomized controlled trials, high-dose chemotherapy followed by ASCT has been established as the standard of care for patients with relapsed or refractory HL.

Although the indication of ASCT for patients with relapsed disease is supported by randomized trials, there are no randomized data with regard to the optimal salvage therapy and conditioning regimens. A concern with the use of melphalan-containing salvage regimens, such as mini-BEAM or Dexa-BEAM which were used in the two randomized ASCT trials, is the relatively high treatmentrelated mortality (TRM) and bone marrow toxicity, which may compromise adequate stem cell collection in preparation for ASCT. ${ }^{109-111}$ Therefore, alternative chemotherapy regimens incorporating non-cross-resistant agents have been extensively studied as salvage treatment for cytoreduction before ASCT. The combination of ifosfamide, carboplatin and etoposide (ICE) was developed at Memorial Sloan Kettering Cancer Center ${ }^{8,112}$ and is one of the most commonly used salvage regimens for HL. In a cohort of 65 patients with relapsed/refractory HL, two cycles of ICE given every 2 weeks were associated with an OR rate of $88 \%$ and resulted in a long-term EFS of $68 \%$ in 57 patients who proceeded to ASCT incorporating involved-field radiation therapy. ${ }^{8} \mathrm{An}$ augmented ICE regimen with intensified doses of ifosfamide and etoposide has also been employed for patients with unfavorable risk factors. ${ }^{74,113}$ Other commonly used salvage regimens include combinations of platinum agents with cytarabine, such as dexamethasone, cisplatin and cytarabine (DHAP), ${ }^{114}$ or etoposide, methylprednisolone, cytarabine and cisplatin (ESHAP). ${ }^{115,116}$ Gemcitabine-based chemotherapy regimens have also been developed, such as gemcitabine, dexamethasone and cisplatin (GDP), ${ }^{117}$ gemcitabine and vinorelbine $(\mathrm{GV}),{ }^{118} \mathrm{GV}$ with doxorubicin $(\mathrm{GVD}){ }^{119}$ or ifosfamide, gemcitabine and vinorelbine (IGeV). ${ }^{120}$ Such gemcitabine-based regimens offer the advantage of outpatient administration, and there is some evidence that may achieve similar response rates and superior PFS compared to mini-BEAM, with less toxicity. ${ }^{111}$

The advent of new targeted or immunotherapy agents for relapsed/refractory HL (detailed in the "Novel therapeutic approaches for primary refractory and early relapsed HL" section) has been embraced with enthusiasm, because they offer the potential for effective salvage therapy without excessive toxicity, in contrast to conventional cytotoxic chemotherapy. There is currently no consensus with regard to the optimal salvage strategy for patients with relapsed/refractory HL. However, given the importance of pretransplant disease status for posttransplant outcomes, it is reasonable to attempt a second non-cross-resistant regimen in patients with inadequate response to first salvage, with the goal to achieve CR prior to ASCT.

A variety of conditioning regimens have been used for ASCT in patients with relapsed or refractory HL, but there is no agreement with regard to optimal regimen. The two Phase III prospective randomized studies that established the role of ASCT in such patients used BEAM conditioning, ${ }^{106,107}$ which remains one of the most commonly used regimens to date. Other common regimens include cyclophosphamide, carmustine and etoposide (CBV) with various dosing modifications ${ }^{121-125}$; busulfan-based regimens such as busulfan and cyclophosphamide (BuCy), ${ }^{126}$ busulfan and melphalan (BuMel) ${ }^{127}$ busulfan, etoposide and cyclophosphamide $(\mathrm{BuCyE})^{128,129}$ a or triple alkylator regimen of busulfan, melphalan and thiotepa (BuMelTt) ${ }^{130,131}$ total body irradiation (TBI) (or total lymphoid irradiation [TLI])-based regimens have also been used as conditioning regimens in previously nonirradiated patients ${ }^{8,113,123,132,133}$; however, there 
has been a swift away from such regimens over time due to concerns for increased associated risk of secondary malignancies and long-term toxicity. Based on registry analyses, BEAM appears to be superior to CBV, TBI-based therapies, or BuCyE as a preparative regimen in patients with HL undergoing ASCT. ${ }^{129,134}$

\section{Prognostic factors for patients with relapsed/refractory HL undergoing ASCT}

Considering different combinations of salvage and conditioning regimens, many single-arm studies or retrospective analyses support the role of ASCT in patients with relapsed and/ or refractory HL, which was previously established by two prospective Phase III studies in relapsed HL patients. ${ }^{135-138}$ Moreover, several such studies have sought to identify prognostic factors for ASCT outcomes. Prognostic factors can be divided into patient-related, disease-related at the time of disease relapse or progression, and factors related to disease status prior to ASCT. Age and performance status are the most important patient-related factors and likely influence the risk of TRM. ${ }^{139-141}$ Factors at the time of disease relapse or progression that have been associated with clinical outcomes include duration of remission, anemia, B-symptomatology, stage IV disease or extranodal involvement and bulky disease. ${ }^{8,139,140,142-144}$ Although primary refractory HL is thought to confer worse prognosis, such patients may also derive benefit from ASCT, depending on the risk factors present. ${ }^{145,146}$

Importantly, pre-ASCT factors such as the number of salvage chemotherapy lines, stage and response to salvage therapy are important prognostic factors for post-ASCT outcomes. ${ }^{138,147}$ Functional imaging by Gallium scans in the past or, most commonly, by fluorodeoxyglucose (FDG)positron emission tomography (FDG-PET) is preferred over computed tomography (CT) for assessment of response to salvage therapy, because it can differentiate viable tumor from residual fibrotic tissue in patients with PR to therapy by $\mathrm{CT} .{ }^{142}$ Moreover, several groups have shown that normalization of pre-ASCT functional imaging and, in particular, FDG-PET is an independent prognostic factor for post-ASCT risk of relapse, PFS and possibly OS, and may be superior to other risk factors at the time of relapse. ${ }^{141,148-151}$ These findings were corroborated in a recent meta-analysis. ${ }^{152}$ Based on the notion that FDG-PET response to salvage therapy is predictive of clinical outcomes, MSKCC has performed two Phase II studies of PET-adapted sequential salvage therapy, ${ }^{74,113}$ in which patients with relapsed or refractory HL who did not achieve CR to first salvage therapy were switched to a different salvage regimen prior to ASCT. PET-adapted salvage strategies may increase the proportion of patients achieving FDG-PET negativity and consequently leading to higher chances of cure. However, such strategies may be limited by the inadequate sensitivity and specificity of the test. ${ }^{152}$

\section{ASCT for frontline consolidation of patients with high-risk $\mathrm{HL}$}

In view of the improved outcomes of ASCT in relapsed or refractory HL and early data in the preemptive setting, ${ }^{153}$ subsequent randomized clinical trials tested ASCT as a consolidation strategy for patients with unfavorable high-risk HL in first CR or PR, in comparison with standard induction chemotherapy ${ }^{154,155}$ or intensified induction with or without radiotherapy. ${ }^{156}$ Despite the different definitions of adverse risk factors, neither study showed a failure-free or a survival benefit in patients receiving frontline ASCT, suggesting that a large fraction of patients with nonchemorefractory unfavorable HL are cured with standard induction chemotherapy or effectively salvaged with ASCT at the time of relapse. Consequently, despite prior controversy, ${ }^{153,157-159}$ ASCT is not recommended for frontline consolidation in patients with advanced or high-risk HL responding to induction chemotherapy.

\section{Intensification of salvage and sequential high-dose chemotherapy (SHDCT)}

Approximately $30-50 \%$ of patients with relapsed or refractory HL undergoing ASCT will eventually develop disease progression after transplant. The risk is influenced by the presence of disease-related risk factors and, possibly, by the type of the conditioning regimen. ${ }^{134,160,161}$ Some investigators have favored more intensive salvage regimens prior to $\mathrm{ASCT}^{135,162}$ with variable results. However, in the absence of prospective comparative trials, such approaches have not been widely adopted. A Phase III European intergroup study investigated whether SHDCT - consisting of sequential high doses of cyclophosphamide, methotrexate and etoposide administered to patients responding to two cycles of ESHAP before BEAM ASCT - might decrease the risk of post-ASCT relapse. ${ }^{163}$ The intervention was proven toxic without survival benefit. Thus, intensification of conditioning did not lead to improved ASCT outcomes.

\section{Tandem ASCT for relapsed/refractory ASCT}

The use of tandem ASCT has also been investigated as a strategy to improve the outcomes in patients with relapsed 
or refractory HL. In the prospective Phase II GELA/SFGM H96 trial, poor-risk patients ${ }^{164}$ received salvage treatment followed by tandem ASCT 45-90 days apart. ${ }^{165}$ The first conditioning was $\mathrm{CBV}$ with mitoxantrone (CBVM) or BEAM, and the second was TBI, cytarabine (Ara-C) and melphalan (TAM) or busulfan, cytarabine (Ara-C) and melphalan (BAM) in patients who had received prior irradiation. Long-term follow-up results of the trial showed $46 \%$ and $57 \%$ freedom from second failure and OS at 5 years, and $41 \%$ and $47 \%$ at 10 years, respectively, which were comparably favorable to the historic rates especially in patients not achieving CR to cytoreductive therapy. ${ }^{165,166}$ Other groups using different salvage and conditioning regimens ${ }^{167,168}$ have similarly suggested that tandem ASCT may be an effective treatment strategy for primary refractory or poor-risk-relapsed HL. However, in the absence of randomized studies and considering the advent of newer effective agents that can be used for salvage or post-ASCT maintenance, tandem ASCT is not routinely performed and has no role in the management of standard risk patients in particular.

\section{Post-ASCT maintenance}

An alternative strategy to improve the outcomes of ASCT consists of the use of post-ASCT consolidation or maintenance. Early attempts with the use of cytotoxic chemotherapy ${ }^{169}$ or immunotherapeutic agents (rIL-2 and IFN- $\left.\alpha\right)^{170}$ were not widely adopted due to lack of efficacy or tolerability. In contrast, the multicenter Phase III AETHERA trial evaluated the use of brentuximab vedotin as post-ASCT maintenance therapy in 329 patients with primary refractory or unfavorable-risk-relapsed HL, defined as $<12$ month initial remission duration or extranodal involvement prior to salvage chemotherapy. ${ }^{142}$ Patients were randomized to receive brentuximab vedotin for up to 1 year versus placebo. Patients randomized to the treatment arm had significantly improved 2 -year PFS of $63 \%$ by independent review compared to $51 \%$ in the placebo group. The PFS benefit of brentuximab vedotin maintenance was consistent across subgroups, although less notable in patients who achieved PET-negative remission before ASCT. No OS benefit was observed, but the majority of control patients received brentuximab vedotin at the time of progression. Based on the results of the AETHERA trial, brentuximab vedotin has received FDA approval for post-ASCT maintenance in patients with HL at high risk for relapse or progression. The use of other targeted agents, including HDAC inhibitors and PD-1 inhibitors, for consolidation is appealing given the high response rates and favorable side- effect profile of such agents, but their role in this setting remains to be shown.

\section{Allogeneic stem cell transplantation (alloHCT)}

Patients who relapse after ASCT have poor prognosis and, in general, they are not considered curable with standard chemotherapy. ${ }^{10,14}$ Perhaps the only exception includes patients with truly localized disease that may be salvaged with radiation. ${ }^{171}$ A second ASCT may be considered for post-ASCT-relapsed HL patients, ${ }^{172}$ especially in those who have had a long remission interval following first ASCT. However, alloHCT has been most commonly considered for such patients as a potentially curative intervention.

Early experience with myeloablative (MAC) alloHCT in HL patients was associated with limited success due to high rates of TRM and relapse, likely due to the inclusion of heavily pretreated or advanced HL patients. ${ }^{173,174}$ Moreover, alloHCT was not found to be superior to ASCT in terms of survival outcomes. ${ }^{175,176}$ Consequently, alloHCT is not recommenced in lieu of ASCT in the management of relapsed/ refractory $\mathrm{HL}$ and is reserved for carefully selected medically fit patients relapsing after ASCT.

More recently, reduced intensity conditioning (RIC) alloHCT, commonly with the use of fludarabine and melphalan or BEAM conditioning, with or without in vivo T-cell depletion, has been embraced by many centers due to the lower risk of TRM and is considered the recommended approach for patients with relapsed HL who are candidates for alloHCT. ${ }^{177-181}$ This recommendation is also supported by a retrospective analysis by the Lymphoma Working Party of the European Group for Blood and Marrow Transplantation, which demonstrated significantly lower TRM and improved OS survival with RIC compared to MAC alloHCT. ${ }^{182}$ Prognostic factors for TRM included chemorefractory disease, poor performance status and age $>45$ years, whereas PFS and OS determinants included performance status and disease status at transplant. ${ }^{183}$ However, it should be noted that in a more recent analysis, MAC alloHCT was associated with a nonsignificant improvement in PFS due to somewhat better disease control and decreasing TRM in recent years. Consequently, the issue of conditioning intensity may be revised in the future. ${ }^{184}$ Despite recent improvements, the optimal conditioning regimen for patients undergoing alloHCT for HL remains undetermined, and relapse continues to be a common cause of treatment failure. Finally, patients who relapse after alloHCT have limited treatment options including donor lymphocyte infusions (DLIs), second alloHCT, radiation 
therapy and palliative chemotherapy, and, in general, their prognosis is grim. ${ }^{185,186}$

There is conflicting evidence regarding the susceptibility of HL to graft versus lymphoma (GVL) effect, which is more crucial in the setting of RIC alloHCT. In support of a potent GVL effect, some studies have shown high rates of clinical responses in heavily treated allografted HL patients to $\mathrm{DLI}^{187,188}$ and a reduction in relapse risk in allografted patients developing acute or chronic graft versus host disease (GVHD). ${ }^{175,182,183}$ However, a large Center for International Blood and Marrow Transplant Research (CIBMTR) study showed no association between GVHD and reduction of relapse risk after MAC or RIC alloHCT for HL arguing against a potent GVL effect in these patients. ${ }^{189}$ Moreover, relapse risk remains high for allografted HL patients (especially in comparison with indolent lymphomas). ${ }^{190}$

Although most of the alloHCT experience for HL (and other lymphomas) is based on patients transplanted with HLA-matched related or unrelated donors, several patients lack suitable HLA-matched donors. Alternative graft sources including mismatched unrelated donors, haploidenticalrelated donors and unrelated cord blood have extended allograft access to patients with lymphoma (including HL), with acceptable and largely comparable results to matched unrelated donor transplants. ${ }^{191-193}$ Similarly, although data specific to HL patient cohorts allografted with alternative donors are more limited, they support the notion that all graft sources can be considered in patients who are felt to be candidates for a potentially curative alloHCT. ${ }^{194-198}$

In view of the development of novel targeted agents with high activity against HL and favorable side-effect profiles, it is likely that alloHCT may play a lesser role in the management of such patients in the proximate future. Moreover, questions remain unanswered regarding the incorporation and optimal sequence of new agents in the treatment plan, without compromising safety. As an example, brentuximab vedotin has been successfully used prior to allogeneic transplantation ${ }^{199,200}$ as a single agent or in combination with DLI for post-alloHCT relapse. ${ }^{201,202}$ In contrast, PD-1 blockade prior to or after alloHCT may exacerbate GVHD due to prolonged or permanent inhibition of pathways with a key role in the induction of self-tolerance. ${ }^{203,204}$

\section{Summary and future directions}

In summary, HL is a highly curable disease, but $25 \%-30 \%$ of patients will progress during or following first-line chemotherapy and will require further treatment. High-dose chemotherapy followed by ASCT remains the standard of care for patients with relapsed or refractory HL who respond to salvage therapy, and affords long-term PFS in $~ 50 \%$ of such patients, but ASCT success varies widely depending on the risk factors present and pre-ASCT disease status. There is presently not enough evidence to support a routine role of upfront ASCT in high-risk HL, SHDCT or tandem ASCT. HL relapsing after ASCT is associated with adverse prognosis, and alloHCT in that setting is the only potentially curative treatment modality, although historically limited by high rates of TRM and associated morbidity. Recent advancements in the understanding of HL pathogenesis and the development of novel targeted therapies with promising efficacy and favorable toxicity profiles have provided hope for improving the outcomes of patients with relapsed or refractory HL. Such novel therapies, including brentuximab vedotin and PD-1 inhibitors, have been successfully incorporated in the current treatment paradigm, specifically as salvage therapy of HL patients relapsing after frontline therapy, as post-ASCT maintenance for relapsed or refractory HL with high-risk features and as bridge therapy prior to ASCT or AlloSCT, either alone or in combination with other agents. Moreover, in view of the promising results of such agents, the role of AlloSCT for the management of relapsed or refractory HL might need to be revised. Nevertheless, although the development of numerous novel agents with activity against HL is exciting, further studies are required to determine their long-term efficacy and the optimal combination or sequence of such therapies, ideally in a risk-adapted fashion.

\section{Acknowledgment}

This work was supported by National Institutes of Health grants CA183605, CA183605S1 and AI098129-01 and by the DoD grant PC140571.

\section{Disclosure}

Vassiliki A Boussiotis has patents on the PD-1 pathway licensed by Bristol-Myers Squibb, Roche, Merck, EMDSerono, Boehringer Ingelheim, AstraZeneca, Novartis and Dako. The authors report no other conflicts of interest in this work.

\section{References}

1. Hjalgrim H, Engels EA. Infectious aetiology of Hodgkin and nonHodgkin lymphomas: a review of the epidemiological evidence. $J$ Intern Med. 2008;264(6):537-548.

2. Foss HD, Reusch R, Demel G, et al. Frequent expression of the B-cell-specific activator protein in Reed-Sternberg cells of classical Hodgkin's disease provides further evidence for its B-cell origin. Blood. 1999;94(9):3108-3113. 
3. Liu Y, Sattarzadeh A, Diepstra A, Visser L, van den Berg A. The microenvironment in classical Hodgkin lymphoma: an actively shaped and essential tumor component. Semin Cancer Biol. 2014;24:15-22.

4. Steidl C, Connors JM, Gascoyne RD. Molecular pathogenesis of Hodgkin's lymphoma: increasing evidence of the importance of the microenvironment. J Clin Oncol. 2011;29(14):1812-1826.

5. Santoro A, Bonadonna G, Valagussa $\mathrm{P}$, et al. Long-term results of combined chemotherapy-radiotherapy approach in Hodgkin's disease: superiority of ABVD plus radiotherapy versus MOPP plus radiotherapy. J Clin Oncol. 1987;5(1):27-37.

6. Engert A, Plutschow A, Eich HT, et al. Reduced treatment intensity in patients with early-stage Hodgkin's lymphoma. $N$ Engl J Med. 2010;363(7):640-652.

7. Canellos GP, Rosenberg SA, Friedberg JW, Lister TA, Devita VT. Treatment of Hodgkin lymphoma: a 50-year perspective. JClin Oncol. 2014;32(3):163-168.

8. Moskowitz CH, Nimer SD, Zelenetz AD, et al. A 2-step comprehensive high-dose chemoradiotherapy second-line program for relapsed and refractory Hodgkin disease: analysis by intent to treat and development of a prognostic model. Blood. 2001;97(3):616-623.

9. Viviani S, Di Nicola M, Bonfante V, et al. Long-term results of highdose chemotherapy with autologous bone marrow or peripheral stem cell transplant as first salvage treatment for relapsed or refractory Hodgkin lymphoma: a single institution experience. Leuk Lymphoma 2010;51(7):1251-1259.

10. Moskowitz AJ, Perales MA, Kewalramani T, et al. Outcomes for patients who fail high dose chemoradiotherapy and autologous stem cell rescue for relapsed and primary refractory Hodgkin lymphoma. Br J Haematol. 2009;146(2):158-163.

11. Crump M. Management of Hodgkin lymphoma in relapse after autologous stem cell transplant. Hematology Am Soc Hematol Educ Program. 2008:326-333.

12. Younes A, Bartlett NL, Leonard JP, et al. Brentuximab vedotin (SGN-35) for relapsed CD30-positive lymphomas. $N$ Engl J Med. 2010;363(19):1812-1821.

13. Ansell SM, Lesokhin AM, Borrello I, et al. PD-1 blockade with nivolumab in relapsed or refractory Hodgkin's lymphoma. $N$ Engl $J$ Med. 2015;372(4):311-319.

14. Sarina B, Castagna L, Farina L, et al; Gruppo Italiano Trapianto di Midollo Osseo. Allogeneic transplantation improves the overall and progression-free survival of Hodgkin lymphoma patients relapsing after autologous transplantation: a retrospective study based on the time of HLA typing and donor availability. Blood.2010;115(18):3671-3677.

15. Alvaro T, Lejeune M, Salvado MT, et al. Outcome in Hodgkin's lymphoma can be predicted from the presence of accompanying cytotoxic and regulatory T cells. Clin Cancer Res. 2005;11(4):1467-1473.

16. Alvaro-Naranjo T, Lejeune M, Salvado-Usach MT, et al. Tumorinfiltrating cells as a prognostic factor in Hodgkin's lymphoma: a quantitative tissue microarray study in a large retrospective cohort of 267 patients. Leuk Lymphoma. 2005;46(11):1581-1591.

17. Steidl C, Lee T, Shah SP, et al. Tumor-associated macrophages and survival in classic Hodgkin's lymphoma. $N$ Engl $J$ Med. 2010;362(10):875-885.

18. Kamper P, Bendix K, Hamilton-Dutoit S, Honore B, Nyengaard JR, d'Amore F. Tumor-infiltrating macrophages correlate with adverse prognosis and Epstein-Barr virus status in classical Hodgkin's lymphoma. Haematologica. 2011;96(2):269-276.

19. Clarke CA, Glaser SL, Dorfman RF, et al. Epstein-Barr virus and survival after Hodgkin disease in a population-based series of women Cancer. 2001;91(8):1579-1587.

20. Stark GL, Wood KM, Jack F, et al; Northern Region Lymphoma Group. Hodgkin's disease in the elderly: a population-based study. Br J Haematol. 2002;119(2):432-440.

21. Kryczek I, Zou L, Rodriguez P, et al. B7-H4 expression identifies a novel suppressive macrophage population in human ovarian carcinoma. J Exp Med. 2006;203(4):871-881.
22. Kuang DM, Zhao Q, Peng C, et al. Activated monocytes in peritumoral stroma of hepatocellular carcinoma foster immune privilege and disease progression through PD-L1. J Exp Med. 2009;206(6):1327-1337.

23. Curiel TJ, Coukos G, Zou L, et al. Specific recruitment of regulatory $\mathrm{T}$ cells in ovarian carcinoma fosters immune privilege and predicts reduced survival. Nat Med. 2004;10(9):942-949.

24. Carbone A, Gloghini A, Castagna L, Santoro A, Carlo-Stella C. Primary refractory and early-relapsed Hodgkin's lymphoma: strategies for therapeutic targeting based on the tumour microenvironment. $J$ Pathol. 2015;237(1):4-13.

25. Kelley TW, Pohlman B, Elson P, Hsi ED. The ratio of FOXP3+ regulatory $\mathrm{T}$ cells to granzyme $\mathrm{B}+$ cytotoxic $\mathrm{T} / \mathrm{NK}$ cells predicts prognosis in classical Hodgkin lymphoma and is independent of bcl-2 and MAL expression. Am J Clin Pathol. 2007;128(6):958-965.

26. Alonso-Alvarez S, Vidriales MB, Caballero MD, et al. The number of tumor infiltrating T-cell subsets in lymph nodes from patients with Hodgkin lymphoma is associated with the outcome after first line ABVD therapy. Leuk Lymphoma. 2017;58(5):1144-1152.

27. Re D, Kuppers R, Diehl V. Molecular pathogenesis of Hodgkin's lymphoma. J Clin Oncol. 2005;23(26):6379-6386.

28. Skinnider BF, Mak TW. The role of cytokines in classical Hodgkin lymphoma. Blood. 2002;99(12):4283-4297.

29. Kuppers R. The biology of Hodgkin's lymphoma. Nat Rev Cancer. 2009;9(1):15-27.

30. de la Cruz-Merino L, Lejeune M, Nogales Fernandez E, et al. Role of immune escape mechanisms in Hodgkin's lymphoma development and progression: a whole new world with therapeutic implications. Clin Dev Immunol. 2012;2012:756353.

31. Aldinucci D, Gloghini A, Pinto A, De Filippi R, Carbone A. The classical Hodgkin's lymphoma microenvironment and its role in promoting tumour growth and immune escape. J Pathol. 2010;221(3):248-263.

32. Poppema S. Immunobiology and pathophysiology of Hodgkin lymphomas. Hematology Am Soc Hematol Educ Program. 2005:231-238.

33. Aldinucci D, Lorenzon D, Olivo K, Rapana B, Gattei V. Interactions between tissue fibroblasts in lymph nodes and Hodgkin/Reed-Sternberg cells. Leuk Lymphoma. 2004;45(9):1731-1739.

34. Jundt F, Anagnostopoulos I, Bommert K, et al. Hodgkin/ReedSternberg cells induce fibroblasts to secrete eotaxin, a potent chemoattractant for T cells and eosinophils. Blood. 1999;94(6):2065-2071.

35. Xu H, Raynal N, Stathopoulos S, Myllyharju J, Farndale RW, Leitinger B. Collagen binding specificity of the discoidin domain receptors: binding sites on collagens II and III and molecular determinants for collagen IV recognition by DDR1. Matrix Biol. 2011;30(1):16-26.

36. Carbone A, Gloghini A. Activated DDR1 increases RS cell survival. Blood. 2013;122(26):4152-4154.

37. Biggar RJ, Jaffe ES, Goedert JJ, Chaturvedi A, Pfeiffer R, Engels EA. Hodgkin lymphoma and immunodeficiency in persons with HIV/ AIDS. Blood. 2006;108(12):3786-3791.

38. Aldinucci D, Gloghini A, Pinto A, Colombatti A, Carbone A. The role of CD40/CD40L and interferon regulatory factor 4 in Hodgkin lymphoma microenvironment. Leuk Lymphoma. 2012;53(2):195-201.

39. Metkar SS, Naresh KN, Redkar AA, Nadkarni JJ. CD40-ligation-mediated protection from apoptosis of a Fas-sensitive Hodgkin's-diseasederived cell line. Cancer Immunol Immunother. 1998;47(2):104-112.

40. Aldinucci D, Celegato M, Borghese C, Colombatti A, Carbone A. IRF4 silencing inhibits Hodgkin lymphoma cell proliferation, survival and CCL5 secretion. Br J Haematol. 2011;152(2):182-190.

41. Celegato M, Borghese C, Umezawa K, et al. The NF-kappaB inhibitor DHMEQ decreases survival factors, overcomes the protective activity of microenvironment and synergizes with chemotherapy agents in classical Hodgkin lymphoma. Cancer Lett. 2014;349(1):26-34.

42. Celegato M, Borghese C, Casagrande N, Carbone A, Colombatti A, Aldinucci D. Bortezomib down-modulates the survival factor interferon regulatory factor 4 in Hodgkin lymphoma cell lines and decreases the protective activity of Hodgkin lymphoma-associated fibroblasts. Leuk Lymphoma. 2014;55(1):149-159. 
43. Carbone A, Gloghini A, Gattei V, et al. Expression of functional CD40 antigen on Reed-Sternberg cells and Hodgkin's disease cell lines. Blood. 1995;85(3):780-789.

44. Zheng B, Fiumara P, Li YV, et al. MEK/ERK pathway is aberrantly active in Hodgkin disease: a signaling pathway shared by CD30, CD40, and RANK that regulates cell proliferation and survival. Blood. 2003;102(3):1019-1027.

45. Kashkar H, Haefs C, Shin H, et al. XIAP-mediated caspase inhibition in Hodgkin's lymphoma-derived B cells. J Exp Med. 2003;198(2):341-347.

46. Gruss HJ, Ulrich D, Dower SK, Herrmann F, Brach MA. Activation of Hodgkin cells via the CD30 receptor induces autocrine secretion of interleukin-6 engaging the NF-kappabeta transcription factor. Blood. 1996;87(6):2443-2449.

47. Bargou RC, Leng C, Krappmann D, et al. High-level nuclear NF-kappa $\mathrm{B}$ and Oct-2 is a common feature of cultured Hodgkin/Reed-Sternberg cells. Blood. 1996;87(10):4340-4347.

48. Bargou RC, Emmerich F, Krappmann D, et al. Constitutive nuclear factor-kappaB-RelA activation is required for proliferation and survival of Hodgkin's disease tumor cells. J Clin Invest. 1997;100(12):2961-2969.

49. Krappmann D, Emmerich F, Kordes U, Scharschmidt E, Dorken B, Scheidereit C. Molecular mechanisms of constitutive NFkappaB/Rel activation in Hodgkin/Reed-Sternberg cells. Oncogene. 1999;18(4):943-953.

50. Horie R, Watanabe T, Morishita Y, et al. Ligand-independent signaling by overexpressed CD30 drives NF-kappaB activation in HodgkinReed-Sternberg cells. Oncogene. 2002;21(16):2493-2503.

51. Hinz M, Krappmann D, Eichten A, Heder A, Scheidereit C, Strauss M. NF-kappaB function in growth control: regulation of cyclin D1 expression and G0/G1-to-S-phase transition. Mol Cell Biol. 1999;19(4):2690-2698.

52. Duyao MP, Kessler DJ, Spicer DB, et al. Transactivation of the c-myc promoter by human T cell leukemia virus type 1 tax is mediated by NF kappa B. J Biol Chem. 1992;267(23):16288-16291.

53. Toth CR, Hostutler RF, Baldwin AS Jr, Bender TP. Members of the nuclear factor kappa B family transactivate the murine c-myb gene. $J$ Biol Chem. 1995;270(13):7661-7671.

54. Karin M, Lin A. NF-kappaB at the crossroads of life and death. Nat Immunol. 2002;3(3):221-227.

55. Thome M, Tschopp J. Regulation of lymphocyte proliferation and death by FLIP. Nat Rev Immunol. 2001;1(1):50-58.

56. Tiacci E, Doring C, Brune V, et al. Analyzing primary Hodgkin and Reed-Sternberg cells to capture the molecular and cellular pathogenesis of classical Hodgkin lymphoma. Blood. 2012;120(23):4609-4620.

57. Locatelli SL, Careddu G, Inghirami G, et al. The novel PI3K-delta inhibitor TGR-1202 enhances brentuximab vedotin-induced Hodgkin lymphoma cell death via mitotic arrest. Leukemia. 2016;30(12): 2402-2405.

58. Skinnider BF, Elia AJ, Gascoyne RD, et al. Signal transducer and activator of transcription 6 is frequently activated in Hodgkin and ReedSternberg cells of Hodgkin lymphoma. Blood. 2002;99(2):618-626.

59. Holtick U, Vockerodt M, Pinkert D, et al. STAT3 is essential for Hodgkin lymphoma cell proliferation and is a target of tyrphostin AG17 which confers sensitization for apoptosis. Leukemia. 2005; 19(6):936-944.

60. Cochet O, Frelin C, Peyron JF, Imbert V. Constitutive activation of STAT proteins in the HDLM-2 and L540 Hodgkin lymphoma-derived cell lines supports cell survival. Cell Signal. 2006;18(4):449-455.

61. Van Roosbroeck K, Cox L, Tousseyn T, et al. JAK2 rearrangements, including the novel SEC31A-JAK2 fusion, are recurrent in classical Hodgkin lymphoma. Blood. 2011;117(15):4056-4064.

62. Diaz T, Navarro A, Ferrer G, et al. Lestaurtinib inhibition of the Jak/ STAT signaling pathway in hodgkin lymphoma inhibits proliferation and induces apoptosis. PLoS One. 2011;6(4):e18856.

63. Gunawardana J, Chan FC, Telenius A, et al. Recurrent somatic mutations of PTPN1 in primary mediastinal B cell lymphoma and Hodgkin lymphoma. Nat Genet. 2014;46(4):329-335.
64. Schoof N, von Bonin F, Trumper L, Kube D. HSP90 is essential for Jak-STAT signaling in classical Hodgkin lymphoma cells. Cell Commun Signal. 2009;7:17.

65. Green MR, Monti S, Rodig SJ, et al. Integrative analysis reveals selective 9p24.1 amplification, increased PD-1 ligand expression, and further induction via JAK2 in nodular sclerosing Hodgkin lymphoma and primary mediastinal large B-cell lymphoma. Blood. 2010;116(17):3268-3277.

66. Paydas S, Bagir E, Seydaoglu G, Ercolak V, Ergin M. Programmed death-1 (PD-1), programmed death-ligand 1 (PD-L1), and EBVencoded RNA (EBER) expression in Hodgkin lymphoma. Ann Hematol. 2015;94(9):1545-1552.

67. Koh YW, Jeon YK, Yoon DH, Suh C, Huh J. Programmed death 1 expression in the peritumoral microenvironment is associated with a poorer prognosis in classical Hodgkin lymphoma. Tumour Biol. 2016;37(6):7507-7514.

68. Huen DS, Henderson SA, Croom-Carter D, Rowe M. The Epstein-Barr virus latent membrane protein-1 (LMP1) mediates activation of NFkappa B and cell surface phenotype via two effector regions in its carboxy-terminal cytoplasmic domain. Oncogene. 1995;10(3):549-560.

69. Jungnickel B, Staratschek-Jox A, Brauninger A, et al. Clonal deleterious mutations in the IkappaBalpha gene in the malignant cells in Hodgkin's lymphoma. J Exp Med. 2000;191(2):395-402.

70. Portis T, Dyck P, Longnecker R. Epstein-Barr Virus (EBV) LMP2A induces alterations in gene transcription similar to those observed in ReedSternberg cells of Hodgkin lymphoma. Blood. 2003;102(12):4166-4178.

71. Ansell SM. Brentuximab vedotin. Blood. 2014;124(22):3197-3200.

72. Younes A, Gopal AK, Smith SE, et al. Results of a pivotal phase II study of brentuximab vedotin for patients with relapsed or refractory Hodgkin's lymphoma. J Clin Oncol. 2012;30(18):2183-2189.

73. Chen R, Palmer JM, Martin P, et al. Results of a multicenter phase II trial of brentuximab vedotin as second-line therapy before autologous transplantation in relapsed/refractory Hodgkin lymphoma. Biol Blood Marrow Transplant. 2015;21(12):2136-2140.

74. Moskowitz AJ, Schoder H, Yahalom J, et al. PET-adapted sequential salvage therapy with brentuximab vedotin followed by augmented ifosamide, carboplatin, and etoposide for patients with relapsed and refractory Hodgkin's lymphoma: a non-randomised, open-label, singlecentre, phase 2 study. Lancet Oncol. 2015;16(3):284-292.

75. Kalac M, Lue JK, Lichtenstein E, et al. Brentuximab vedotin and bendamustine produce high complete response rates in patients with chemotherapy refractory Hodgkin lymphoma. Br J Haematol. Epub 2016 Dec 16.

76. Chen R, Palmer JM, Tsai NC, et al. Brentuximab vedotin is associated with improved progression-free survival after allogeneic transplantation for Hodgkin lymphoma. Biol Blood Marrow Transplant. 2014;20(11):1864-1868.

77. Gopal AK, Ramchandren R, O'Connor OA, et al. Safety and efficacy of brentuximab vedotin for Hodgkin lymphoma recurring after allogeneic stem cell transplantation. Blood. 2012;120(3):560-568.

78. Younes A, Romaguera J, Fanale M, et al. Phase I study of a novel oral Janus kinase 2 inhibitor, SB1518, in patients with relapsed lymphoma: evidence of clinical and biologic activity in multiple lymphoma subtypes. J Clin Oncol. 2012;30(33):4161-4167.

79. Johnston PB, Inwards DJ, Colgan JP, et al. A Phase II trial of the oral mTOR inhibitor everolimus in relapsed Hodgkin lymphoma. Am J Hematol. 2010;85(5):320-324.

80. Younes A, Oki Y, McLaughlin P, et al. Phase 2 study of rituximab plus ABVD in patients with newly diagnosed classical Hodgkin lymphoma. Blood. 2012;119(18):4123-4128.

81. Kasamon YL, Jacene HA, Gocke CD, et al. Phase 2 study of rituximab-ABVD in classical Hodgkin lymphoma. Blood. 2012;119(18):4129-4132.

82. Smith SM, Schoder H, Johnson JL, et al; Alliance for Clinical Trials in Oncology. The anti-CD80 primatized monoclonal antibody, galiximab, is well-tolerated but has limited activity in relapsed Hodgkin lymphoma: Cancer and Leukemia Group B 50602 (Alliance). Leuk Lymphoma. 2013;54(7):1405-1410. 
83. Blum KA, Johnson JL, Niedzwiecki D, Canellos GP, Cheson BD, Bartlett NL. Single agent bortezomib in the treatment of relapsed and refractory Hodgkin lymphoma: Cancer and Leukemia Group B protocol 50206. Leuk Lymphoma. 2007;48(7):1313-1319.

84. Trelle S, Sezer O, Naumann R, et al. Bortezomib in combination with dexamethasone for patients with relapsed Hodgkin's lymphoma: results of a prematurely closed phase II study (NCT00148018). Haematologica. 2007;92(4):568-569.

85. Mendler JH, Kelly J, Voci S, et al. Bortezomib and gemcitabine in relapsed or refractory Hodgkin's lymphoma. Ann Oncol. 2008;19(10): 1759-1764.

86. Horton TM, Drachtman RA, Chen L, et al. A phase 2 study of bortezomib in combination with ifosfamide/vinorelbine in paediatric patients and young adults with refractory/recurrent Hodgkin lymphoma: a Children's Oncology Group study. Br J Haematol. 2015;170(1):118-122.

87. Fanale M, Fayad L, Pro B, et al. Phase I study of bortezomib plus ICE (BICE) for the treatment of relapsed/refractory Hodgkin lymphoma. Br J Haematol. 2011;154(2):284-286.

88. Fehniger TA, Larson S, Trinkaus K, et al. A phase 2 multicenter study of lenalidomide in relapsed or refractory classical Hodgkin lymphoma. Blood. 2011;118(19):5119-5125.

89. Rueda A, Garcia-Sanz R, Pastor M, et al; Gotel and Geltamo. A phase II study to evaluate lenalidomide in combination with metronomicdose cyclophosphamide in patients with heavily pretreated classical Hodgkin lymphoma. Acta Oncol. 2015;54(6):933-938.

90. Younes A, Santoro A, Shipp M, et al. Nivolumab for classical Hodgkin's lymphoma after failure of both autologous stem-cell transplantation and brentuximab vedotin: a multicentre, multicohort, single-arm phase 2 trial. Lancet Oncol. 2016;17(9):1283-1294.

91. Armand P, Shipp MA, Ribrag V, et al. Programmed death-1 blockade with pembrolizumab in patients with classical Hodgkin lymphoma after brentuximab vedotin failure. J Clin Oncol. 2016;34(31):3733-3739.

92. Lane AA, Chabner BA. Histone deacetylase inhibitors in cancer therapy. J Clin Oncol. 2009;27(32):5459-5468.

93. Buglio D, Younes A. Histone deacetylase inhibitors in Hodgkin lymphoma. Invest New Drugs. 2010;28(suppl 1):S21-S27.

94. Gloghini A, Buglio D, Khaskhely NM, et al. Expression of histone deacetylases in lymphoma: implication for the development of selective inhibitors. Br J Haematol. 2009;147(4):515-525.

95. Younes A, OkiY, Bociek RG, et al. Mocetinostat for relapsed classical Hodgkin's lymphoma: an open-label, single-arm, phase 2 trial. Lancet Oncol. 2011;12(13):1222-1228.

96. Younes A, Sureda A, Ben-Yehuda D, et al. Panobinostat in patients with relapsed/refractory Hodgkin's lymphoma after autologous stem-cell transplantation: results of a phase II study. J Clin Oncol. 2012;30(18):2197-2203.

97. Klein JM, Henke A, Sauer M, et al. The histone deacetylase inhibitor LBH589 (panobinostat) modulates the crosstalk of lymphocytes with Hodgkin lymphoma cell lines. PLoS One. 2013;8(11): e79502.

98. Oki Y, Buglio D, Zhang J, et al. Immune regulatory effects of panobinostat in patients with Hodgkin lymphoma through modulation of serum cytokine levels and T-cell PD1 expression. Blood Cancer J. 2014;4:e236.

99. Lemoine M, Derenzini E, Buglio D, et al. The pan-deacetylase inhibitor panobinostat induces cell death and synergizes with everolimus in Hodgkin lymphoma cell lines. Blood. 2012;119(17):4017-4025.

100. Park H, Garrido-Laguna I, Naing A, et al. Phase I dose-escalation study of the mTOR inhibitor sirolimus and the HDAC inhibitor vorinostat in patients with advanced malignancy. Oncotarget. 2016;7(41):67521-67531.

101. Locatelli SL, Cleris L, Stirparo GG, et al. BIM upregulation and ROSdependent necroptosis mediate the antitumor effects of the HDACi Givinostat and Sorafenib in Hodgkin lymphoma cell line xenografts. Leukemia. 2014;28(9):1861-1871.
102. Longo DL, Duffey PL, Young RC, et al. Conventional-dose salvage combination chemotherapy in patients relapsing with Hodgkin's disease after combination chemotherapy: the low probability for cure. J Clin Oncol. 1992;10(2):210-218.

103. Jagannath S, Dicke KA, Armitage JO, et al. High-dose cyclophosphamide, carmustine, and etoposide and autologous bone marrow transplantation for relapsed Hodgkin's disease. Ann Intern Med. 1986;104(2):163-168.

104. Crump M, Smith AM, Brandwein J, et al. High-dose etoposide and melphalan, and autologous bone marrow transplantation for patients with advanced Hodgkin's disease: importance of disease status at transplant. J Clin Oncol. 1993;11(4):704-711.

105. Chopra R, McMillan AK, Linch DC, et al. The place of high-dose BEAM therapy and autologous bone marrow transplantation in poorrisk Hodgkin's disease. A single-center eight-year study of 155 patients. Blood. 1993;81(5):1137-1145.

106. Linch DC, Winfield D, Goldstone AH, et al. Dose intensification with autologous bone-marrow transplantation in relapsed and resistant Hodgkin's disease: results of a BNLI randomised trial. Lancet 1993;341(8852):1051-1054.

107. Schmitz N, Pfistner B, Sextro M, et al; German Hodgkin's Lymphoma Study Group; Lymphoma Working Party of the European Group for Blood and Marrow Transplantation. Aggressive conventional chemotherapy compared with high-dose chemotherapy with autologous haemopoietic stem-cell transplantation for relapsed chemosensitive Hodgkin's disease: a randomised trial. Lancet. 2002;359(9323):2065-2071.

108. Rancea M, Monsef I, von Tresckow B, Engert A, Skoetz N. Highdose chemotherapy followed by autologous stem cell transplantation for patients with relapsed/refractory Hodgkin lymphoma. Cochrane Database Syst Rev. 2013;(6):Cd009411.

109. Dreger P, Kloss M, Petersen B, et al. Autologous progenitor cell transplantation: prior exposure to stem cell-toxic drugs determines yield and engraftment of peripheral blood progenitor cell but not of bone marrow grafts. Blood. 1995;86(10):3970-3978.

110. Weaver $\mathrm{CH}$, Zhen B, Buckner CD. Treatment of patients with malignant lymphoma with mini-BEAM reduces the yield of CD34+ peripheral blood stem cells. Bone Marrow Transplant. 1998;21(11):1169-1170.

111. Kuruvilla J, Nagy T, Pintilie M, Tsang R, Keating A, Crump M. Similar response rates and superior early progression-free survival with gemcitabine, dexamethasone, and cisplatin salvage therapy compared with carmustine, etoposide, cytarabine, and melphalan salvage therapy prior to autologous stem cell transplantation for recurrent or refractory Hodgkin lymphoma. Cancer. 2006;106(2):353-360.

112. Moskowitz CH, Bertino JR, Glassman JR, et al. Ifosfamide, carboplatin, and etoposide: a highly effective cytoreduction and peripheral-blood progenitor-cell mobilization regimen for transplanteligible patients with non-Hodgkin's lymphoma. J Clin Oncol. 1999; 17(12):3776-3785

113. Moskowitz CH, Matasar MJ, Zelenetz AD, et al. Normalization of pre-ASCT, FDG-PET imaging with second-line, non-cross-resistant, chemotherapy programs improves event-free survival in patients with Hodgkin lymphoma. Blood. 2012;119(7):1665-1670.

114. Josting A, Rudolph C, Reiser M, et al; Participating Centers. Timeintensified dexamethasone/cisplatin/cytarabine: an effective salvage therapy with low toxicity in patients with relapsed and refractory Hodgkin's disease. Ann Oncol. 2002;13(10):1628-1635.

115. Aparicio J, Segura A, Garcera S, et al. ESHAP is an active regimen for relapsing Hodgkin's disease. Ann Oncol. 1999;10(5):593-595.

116. Labrador J, Cabrero-Calvo M, Perez-Lopez E, et al. ESHAP as salvage therapy for relapsed or refractory Hodgkin's lymphoma. Ann Hematol. 2014;93(10):1745-1753.

117. Baetz T, Belch A, Couban S, et al. Gemcitabine, dexamethasone and cisplatin is an active and non-toxic chemotherapy regimen in relapsed or refractory Hodgkin's disease: a phase II study by the National Cancer Institute of Canada Clinical Trials Group. Ann Oncol. 2003;14(12):1762-1767. 
118. Suyani E, Sucak GT, Aki SZ, Yegin ZA, Ozkurt ZN, Yagci M. Gemcitabine and vinorelbine combination is effective in both as a salvage and mobilization regimen in relapsed or refractory Hodgkin lymphoma prior to ASCT. Ann Hematol. 2011;90(6):685-691.

119. Bartlett NL, Niedzwiecki D, Johnson JL, et al; Cancer Leukemia Group B. Gemcitabine, vinorelbine, and pegylated liposomal doxorubicin (GVD), a salvage regimen in relapsed Hodgkin's lymphoma: CALGB 59804. Ann Oncol. 2007;18(6):1071-1079.

120. Santoro A, Magagnoli M, Spina M, et al. Ifosfamide, gemcitabine, and vinorelbine: a new induction regimen for refractory and relapsed Hodgkin's lymphoma. Haematologica. 2007;92(1):35-41.

121. Reece DE, Barnett MJ, Connors JM, et al. Intensive chemotherapy with cyclophosphamide, carmustine, and etoposide followed by autologous bone marrow transplantation for relapsed Hodgkin's disease. J Clin Oncol. 1991;9(10):1871-1879.

122. Bierman PJ, Anderson JR, Freeman MB, et al. High-dose chemotherapy followed by autologous hematopoietic rescue for Hodgkin's disease patients following first relapse after chemotherapy. Ann Oncol. 1996;7(2):151-156.

123. Stiff PJ, Unger JM, Forman SJ, et al; Southwest Oncology Group. The value of augmented preparative regimens combined with an autologous bone marrow transplant for the management of relapsed or refractory Hodgkin disease: a Southwest Oncology Group phase II trial. Biol Blood Marrow Transplant. 2003;9(8):529-539.

124. Arranz R, Tomas JF, Gil-Fernandez JJ, et al. Autologous stem cell transplantation (ASCT) for poor prognostic Hodgkin's disease (HD): comparative results with two $\mathrm{CBV}$ regimens and importance of disease status at transplant. Bone Marrow Transplant. 1998;21(8):779-786.

125. Benekli M, Smiley SL, Younis T, et al. Intensive conditioning regimen of etoposide (VP-16), cyclophosphamide and carmustine (VCB) followed by autologous hematopoietic stem cell transplantation for relapsed and refractory Hodgkin's lymphoma. Bone Marrow Transplant. 2008;41(7):613-619.

126. Lane AA, McAfee SL, Kennedy J, et al. High-dose chemotherapy with busulfan and cyclophosphamide and autologous stem cell rescue in patients with Hodgkin lymphoma. Leuk Lymphoma. 2011;52(7):1363-1366.

127. Kebriaei P, Madden T, Kazerooni R, et al. Intravenous busulfan plus melphalan is a highly effective, well-tolerated preparative regimen for autologous stem cell transplantation in patients with advanced lymphoid malignancies. Biol Blood Marrow Transplant. 2011;17(3):412-420.

128. Wadehra N, Farag S, Bolwell B, et al. Long-term outcome of Hodgkin disease patients following high-dose busulfan, etoposide, cyclophosphamide, and autologous stem cell transplantation. Biol Blood Marrow Transplant. 2006;12(12):1343-1349.

129. Flowers CR, Costa LJ, Pasquini MC, et al. Efficacy of pharmacokinetics-directed busulfan, cyclophosphamide, and etoposide conditioning and autologous stem cell transplantation for lymphoma: comparison of a multicenter phase II study and CIBMTR outcomes. Biol Blood Marrow Transplant. 2016;22(7):1197-1205.

130. Bains T, Chen AI, Lemieux A, et al. Improved outcome with busulfan, melphalan and thiotepa conditioning in autologous hematopoietic stem cell transplant for relapsed/refractory Hodgkin lymphoma. Leuk Lymphoma. 2014;55(3):583-587.

131. Ganguly S, Jain V, Divine C, Aljitawi O, Abhyankar S, McGuirk J. BU, melphalan and thiotepa as a preparative regimen for autotransplantation in Hodgkin's disease. Bone Marrow Transplant. 2012;47(2):311-312.

132. Nademanee A, O'Donnell MR, Snyder DS, et al. High-dose chemotherapy with or without total body irradiation followed by autologous bone marrow and/or peripheral blood stem cell transplantation for patients with relapsed and refractory Hodgkin's disease: results in 85 patients with analysis of prognostic factors. Blood. 1995;85(5):1381-1390.

133. Horning SJ, Chao NJ, Negrin RS, et al. High-dose therapy and autologous hematopoietic progenitor cell transplantation for recurrent or refractory Hodgkin's disease: analysis of the Stanford University results and prognostic indices. Blood. 1997;89(3):801-813.
134. Chen YB, Lane AA, Logan BR, et al. Impact of conditioning regimen on outcomes for patients with lymphoma undergoing high-dose therapy with autologous hematopoietic cell transplantation. Biol Blood Marrow Transplant. 2015;21(6):1046-1053.

135. Ferme C, Mounier N, Divine M, et al. Intensive salvage therapy with high-dose chemotherapy for patients with advanced Hodgkin's disease in relapse or failure after initial chemotherapy: results of the Groupe d'Etudes des Lymphomes de l'Adulte H89 Trial. J Clin Oncol. 2002;20(2):467-475.

136. Vigouroux S, Milpied N, Andrieu JM, et al. Front-line high-dose therapy with autologous stem cell transplantation for high risk Hodgkin's disease: comparison with combined-modality therapy. Bone Marrow Transplant. 2002;29(10):833-842.

137. Lavoie JC, Connors JM, Phillips GL, et al. High-dose chemotherapy and autologous stem cell transplantation for primary refractory or relapsed Hodgkin lymphoma: long-term outcome in the first 100 patients treated in Vancouver. Blood. 2005;106(4): 1473-1478.

138. Czyz J, Dziadziuszko R, Knopinska-Postuszuy W, et al. Outcome and prognostic factors in advanced Hodgkin's disease treated with highdose chemotherapy and autologous stem cell transplantation: a study of 341 patients. Ann Oncol. 2004;15(8):1222-1230.

139. Bierman PJ, Lynch JC, Bociek RG, et al. The International Prognostic Factors Project score for advanced Hodgkin's disease is useful for predicting outcome of autologous hematopoietic stem cell transplantation. Ann Oncol. 2002;13(9):1370-1377.

140. Josting A, Rueffer U, Franklin J, Sieber M, Diehl V, Engert A. Prognostic factors and treatment outcome in primary progressive Hodgkin lymphoma: a report from the German Hodgkin Lymphoma Study Group. Blood. 2000;96(4):1280-1286.

141. Jabbour E, Hosing C, Ayers G, et al. Pretransplant positive positron emission tomography/gallium scans predict poor outcome in patients with recurrent/refractory Hodgkin lymphoma. Cancer. 2007;109(12):2481-2489.

142. Moskowitz CH, Nademanee A, Masszi T, et al; AETHERA Study Group. Brentuximab vedotin as consolidation therapy after autologous stem-cell transplantation in patients with Hodgkin's lymphoma at risk of relapse or progression (AETHERA): a randomised, double-blind, placebo-controlled, phase 3 trial. Lancet. 2015;385(9980):1853-1862.

143. Hahn T, McCarthy PL, Carreras J, et al. Simplified validated prognostic model for progression-free survival after autologous transplantation for hodgkin lymphoma. Biol Blood Marrow Transplant. 2013;19(12): 1740-1744.

144. Popat U, Hosing C, Saliba RM, et al. Prognostic factors for disease progression after high-dose chemotherapy and autologous hematopoietic stem cell transplantation for recurrent or refractory Hodgkin's lymphoma. Bone Marrow Transplant. 2004;33(10):1015-1023.

145. Puig N, Pintilie M, Seshadri T, et al. Different response to salvage chemotherapy but similar post-transplant outcomes in patients with relapsed and refractory Hodgkin's lymphoma. Haematologica. 2010;95(9):1496-1502.

146. Shah GL, Yahalom J, Matasar MJ, et al. Risk factors predicting outcomes for primary refractory hodgkin lymphoma patients treated with salvage chemotherapy and autologous stem cell transplantation. $\mathrm{Br} J$ Haematol. 2016;175(3):440-447.

147. Sureda A, Arranz R, Iriondo A, et al. Autologous stem-cell transplantation for Hodgkin's disease: results and prognostic factors in 494 patients from the Grupo Espanol de Linfomas/Transplante Autologo de Medula Osea Spanish Cooperative Group. J Clin Oncol. 2001; 19(5):1395-1404.

148. Moskowitz AJ, Yahalom J, Kewalramani T, et al. Pretransplantation functional imaging predicts outcome following autologous stem cell transplantation for relapsed and refractory Hodgkin lymphoma. Blood. 2010;116(23):4934-4937.

149. Cocorocchio E, Peccatori F, Vanazzi A, et al. High-dose chemotherapy in relapsed or refractory Hodgkin lymphoma patients: a reappraisal of prognostic factors. Hematol Oncol. 2013;31(1):34-40. 
150. Smeltzer JP, Cashen AF, Zhang Q, et al. Prognostic significance of FDGPET in relapsed or refractory classical Hodgkin lymphoma treated with standard salvage chemotherapy and autologous stem cell transplantation. Biol Blood Marrow Transplant. 2011;17(11):1646-1652.

151. Castagna L, Bramanti S, Balzarotti M, et al. Predictive value of early 18F-fluorodeoxyglucose positron emission tomography (FDG-PET) during salvage chemotherapy in relapsing/refractory Hodgkin lymphoma (HL) treated with high-dose chemotherapy. Br J Haematol. 2009;145(3):369-372.

152. Adams HJ, Kwee TC. Prognostic value of pretransplant FDG-PET in refractory/relapsed Hodgkin lymphoma treated with autologous stem cell transplantation: systematic review and meta-analysis. Ann Hematol. 2016;95(5):695-706.

153. Carella AM, Carlier P, Congiu A, et al. Autologous bone marrow transplantation as adjuvant treatment for high-risk Hodgkin's disease in first complete remission after MOPP/ABVD protocol. Bone Marrow Transplant. 1991;8(2):99-103.

154. Federico M, Bellei M, Brice P, et al; EBMT/GISL/ANZLG/SFGM/ GELA Intergroup HD01 Trial. High-dose therapy and autologous stem-cell transplantation versus conventional therapy for patients with advanced Hodgkin's lymphoma responding to front-line therapy. J Clin Oncol. 2003;21(12):2320-2325.

155. Carella AM, Bellei M, Brice P, et al. High-dose therapy and autologous stem cell transplantation versus conventional therapy for patients with advanced Hodgkin's lymphoma responding to front-line therapy: longterm results. Haematologica. 2009;94(1):146-148.

156. Arakelyan N, Berthou C, Desablens B, et al. Early versus late intensification for patients with high-risk Hodgkin lymphoma-3 cycles of intensive chemotherapy plus low-dose lymph node radiation therapy versus 4 cycles of combined doxorubicin, bleomycin, vinblastine, and dacarbazine plus myeloablative chemotherapy with autologous stem cell transplantation: five-year results of a randomized trial on behalf of the GOELAMS Group. Cancer. 2008;113(12): 3323-3330.

157. Sureda A, Mataix R, Hernandez-Navarro F, et al. Autologous stem cell transplantation for poor prognosis Hodgkin's disease in first complete remission: a retrospective study from the Spanish GELTAMO cooperative group. Bone Marrow Transplant. 1997;20(4): 283-288

158. Fleury J, Legros M, Colombat P, et al. High-dose therapy and autologous bone marrow transplantation in first complete or partial remission for poor prognosis Hodgkin's disease. Leuk Lymphoma. 1996;20(3-4): 259-266.

159. Moreau P, Fleury J, Brice P, et al. Early intensive therapy with autologous stem cell transplantation in advanced Hodgkin's disease: retrospective analysis of 158 cases from the French registry. Bone Marrow Transplant. 1998;21(8):787-793.

160. Majhail NS, Weisdorf DJ, Defor TE, et al. Long-term results of autologous stem cell transplantation for primary refractory or relapsed Hodgkin's lymphoma. Biol Blood Marrow Transplant. 2006; 12(10):1065-1072.

161. Sirohi B, Cunningham D, Powles R, et al. Long-term outcome of autologous stem-cell transplantation in relapsed or refractory Hodgkin's lymphoma. Ann Oncol. 2008;19(7):1312-1319.

162. Shafey M, Duan Q, Russell J, Duggan P, Balogh A, Stewart DA. Double high-dose therapy with dose-intensive cyclophosphamide, etoposide, cisplatin (DICEP) followed by high-dose melphalan and autologous stem cell transplantation for relapsed/refractory Hodgkin lymphoma. Leuk Lymphoma. 2012;53(4):596-602.

163. Josting A, Muller H, Borchmann P, et al. Dose intensity of chemotherapy in patients with relapsed Hodgkin's lymphoma. J Clin Oncol. 2010;28(34):5074-5080.

164. Brice P, Divine M, Simon D, et al. Feasibility of tandem autologous stem-cell transplantation (ASCT) in induction failure or very unfavorable (UF) relapse from Hodgkin's disease (HD). SFGM/GELA Study Group. Ann Oncol. 1999;10(12):1485-1488.
165. Morschhauser F, Brice P, Ferme C, et al; GELA/SFGM Study Group. Risk-adapted salvage treatment with single or tandem autologous stemcell transplantation for first relapse/refractory Hodgkin's lymphoma: results of the prospective multicenter H96 trial by the GELA/SFGM study group. J Clin Oncol. 2008;26(36):5980-5987.

166. Sibon D, Morschhauser F, Resche-Rigon M, et al. Single or tandem autologous stem-cell transplantation for first-relapsed or refractory Hodgkin lymphoma: 10-year follow-up of the prospective H96 trial by the LYSA/SFGM-TC study group. Haematologica. 2016;101(4):474-481.

167. Castagna L, Magagnoli M, Balzarotti M, et al. Tandem high-dose chemotherapy and autologous stem cell transplantation in refractory/ relapsed Hodgkin's lymphoma: a monocenter prospective study. $\mathrm{Am}$ J Hematol. 2007;82(2):122-127.

168. Fung HC, Stiff P, Schriber J, et al. Tandem autologous stem cell transplantation for patients with primary refractory or poor risk recurrent Hodgkin lymphoma. Biol Blood Marrow Transplant. 2007;13(5): 594-600.

169. Rapoport AP, Guo C, Badros A, et al. Autologous stem cell transplantation followed by consolidation chemotherapy for relapsed or refractory Hodgkin's lymphoma. Bone Marrow Transplant. 2004;34(10): 883-890.

170. Nagler A, Berger R, Ackerstein A, et al. A randomized controlled multicenter study comparing recombinant interleukin 2 (rIL-2) in conjunction with recombinant interferon alpha (IFN-alpha) versus no immunotherapy for patients with malignant lymphoma postautologous stem cell transplantation. J Immunother. 2010;33(3):326-333.

171. Goda JS, Massey C, Kuruvilla J, et al. Role of salvage radiation therapy for patients with relapsed or refractory Hodgkin lymphoma who failed autologous stem cell transplant. Int J Radiat Oncol Biol Phys. 2012;84(3):e329-e335.

172. Smith SM, van Besien K, Carreras J, et al. Second autologous stem cell transplantation for relapsed lymphoma after a prior autologous transplant. Biol Blood Marrow Transplant. 2008;14(8):904-912.

173. Gajewski JL, Phillips GL, Sobocinski KA, et al. Bone marrow transplants from HLA-identical siblings in advanced Hodgkin's disease. J Clin Oncol. 1996;14(2):572-578.

174. Anderson JE, Litzow MR, Appelbaum FR, et al. Allogeneic, syngeneic, and autologous marrow transplantation for Hodgkin's disease: the 21-year Seattle experience. J Clin Oncol. 1993;11(12): 2342-2350

175. Milpied N, Fielding AK, Pearce RM, Ernst P, Goldstone AH. Allogeneic bone marrow transplant is not better than autologous transplant for patients with relapsed Hodgkin's disease. European Group for Blood and Bone Marrow Transplantation. J Clin Oncol. 1996;14(4):1291-1296.

176. Peniket AJ, Ruiz de Elvira MC, Taghipour G, et al; European Bone Marrow Transplantation (EBMT) Lymphoma Registry. An EBMT registry matched study of allogeneic stem cell transplants for lymphoma: allogeneic transplantation is associated with a lower relapse rate but a higher procedure-related mortality rate than autologous transplantation. Bone Marrow Transplant. 2003;31(8):667-678.

177. Anderlini P, Saliba R, Acholonu S, et al. Fludarabine-melphalan as a preparative regimen for reduced-intensity conditioning allogeneic stem cell transplantation in relapsed and refractory Hodgkin's lymphoma: the updated M.D. Anderson Cancer Center experience. Haematologica. 2008;93(2):257-264.

178. Alvarez I, Sureda A, Caballero MD, et al. Nonmyeloablative stem cell transplantation is an effective therapy for refractory or relapsed Hodgkin lymphoma: results of a Spanish prospective cooperative protocol. Biol Blood Marrow Transplant. 2006;12(2): 172-183.

179. Chen R, Palmer JM, Popplewell L, et al. Reduced intensity allogeneic hematopoietic cell transplantation can induce durable remission in heavily pretreated relapsed Hodgkin lymphoma. Ann Hematol. 2011;90(7): 803-808. 
180. Peggs KS, Sureda A, Qian W, et al; UK and Spanish Collaborative Groups. Reduced-intensity conditioning for allogeneic haematopoietic stem cell transplantation in relapsed and refractory Hodgkin lymphoma: impact of alemtuzumab and donor lymphocyte infusions on long-term outcomes. Br J Haematol. 2007;139(1):70-80.

181. Kuruvilla J, Pintilie M, Stewart D, et al. Outcomes of reduced-intensity conditioning allo-SCT for Hodgkin's lymphoma: a national review by the Canadian Blood and Marrow Transplant Group. Bone Marrow Transplant. 2010;45(7):1253-1255.

182. Sureda A, Robinson S, Canals C, et al. Reduced-intensity conditioning compared with conventional allogeneic stem-cell transplantation in relapsed or refractory Hodgkin's lymphoma: an analysis from the Lymphoma Working Party of the European Group for Blood and Marrow Transplantation. J Clin Oncol. 2008;26(3):455-462.

183. Robinson SP, Sureda A, Canals C, et al; Lymphoma Working Party of the EBMT. Reduced intensity conditioning allogeneic stem cell transplantation for Hodgkin's lymphoma: identification of prognostic factors predicting outcome. Haematologica. 2009; 94(2):230-238.

184. Genadieva-Stavrik S, Boumendil A, Dreger P, et al. Myeloablative versus reduced intensity allogeneic stem cell transplantation for relapsed/refractory Hodgkin's lymphoma in recent years: a retrospective analysis of the Lymphoma Working Party of the European Group for Blood and Marrow Transplantation. Ann Oncol. 2016;27(12): 2251-2257.

185. Ram R, Gooley TA, Maloney DG, et al. Histology and time to progression predict survival for lymphoma recurring after reduced-intensity conditioning and allogeneic hematopoietic cell transplantation. Biol Blood Marrow Transplant. 2011;17(10):1537-1545.

186. Castagna L, Sarina B, Crocchiolo R, et al. Outcomes of Hodgkin lymphoma patients who relapse after allogeneic stem cell transplantation. Bone Marrow Transplant. 2016;51(12):1644-1646.

187. Peggs KS, Hunter A, Chopra R, et al. Clinical evidence of a graftversus-Hodgkin's-lymphoma effect after reduced-intensity allogeneic transplantation. Lancet. 2005;365(9475):1934-1941.

188. Anderlini P, Acholonu SA, Okoroji GJ, et al. Donor leukocyte infusions in relapsed Hodgkin's lymphoma following allogeneic stem cell transplantation: CD3+ cell dose, GVHD and disease response. Bone Marrow Transplant. 2004;34(6):511-514.

189. Urbano-Ispizua A, Pavletic SZ, Flowers ME, et al. The impact of graft-versus-host disease on the relapse rate in patients with lymphoma depends on the histological subtype and the intensity of the conditioning regimen. Biol Blood Marrow Transplant. 2015;21(10): 1746-1753.

190. Rashidi A, Ebadi M, Cashen AF. Allogeneic hematopoietic stem cell transplantation in Hodgkin lymphoma: a systematic review and metaanalysis. Bone Marrow Transplant. 2016;51(4):521-528.

191. Rodrigues CA, Sanz G, Brunstein CG, et al. Analysis of risk factors for outcomes after unrelated cord blood transplantation in adults with lymphoid malignancies: a study by the Eurocord-Netcord and lymphoma working party of the European group for blood and marrow transplantation. J Clin Oncol. 2009;27(2):256-263.
192. Bachanova V, Burns LJ, Wang T, et al. Alternative donors extend transplantation for patients with lymphoma who lack an HLA matched donor. Bone Marrow Transplant. 2015;50(2):197-203.

193. Kanate AS, Mussetti A, Kharfan-Dabaja MA, et al. Reducedintensity transplantation for lymphomas using haploidentical related donors vs HLA-matched unrelated donors. Blood. 2016;127(7): 938-947.

194. Majhail NS, Weisdorf DJ, Wagner JE, Defor TE, Brunstein CG, Burns LJ. Comparable results of umbilical cord blood and HLA-matched sibling donor hematopoietic stem cell transplantation after reducedintensity preparative regimen for advanced Hodgkin lymphoma. Blood. 2006;107(9):3804-3807.

195. Thompson PA, Perera T, Marin D, et al. Double umbilical cord blood transplant is effective therapy for relapsed or refractory Hodgkin lymphoma. Leuk Lymphoma. 2016;57(7):1607-1615.

196. Burroughs LM, O’Donnell PV, Sandmaier BM, et al. Comparison of outcomes of HLA-matched related, unrelated, or HLA-haploidentical related hematopoietic cell transplantation following nonmyeloablative conditioning for relapsed or refractory Hodgkin lymphoma. Biol Blood Marrow Transplant. 2008;14(11):1279-1287.

197. Gauthier J, Castagna L, Garnier F, et al. Reduced-intensity and nonmyeloablative allogeneic stem cell transplantation from alternative HLA-mismatched donors for Hodgkin lymphoma: a study by the French Society of Bone Marrow Transplantation and Cellular Therapy. Bone Marrow Transplant. Epub 2017 Jan 9.

198. Messer M, Steinzen A, Vervolgyi E, et al. Unrelated and alternative donor allogeneic stem cell transplant in patients with relapsed or refractory Hodgkin lymphoma: a systematic review. Leuk Lymphoma. 2014;55(2):296-306.

199. Anderlini P, Saliba RM, Ledesma C, et al. Gemcitabine, fludarabine, and melphalan for reduced-intensity conditioning and allogeneic stem cell transplantation for relapsed and refractory Hodgkin lymphoma. Biol Blood Marrow Transplant. 2016;22(7):1333-1337.

200. Chen R, Palmer JM, Thomas SH, et al. Brentuximab vedotin enables successful reduced-intensity allogeneic hematopoietic cell transplantation in patients with relapsed or refractory Hodgkin lymphoma. Blood. 2012;119(26):6379-6381.

201. Theurich S, Malcher J, Wennhold K, et al. Brentuximab vedotin combined with donor lymphocyte infusions for early relapse of Hodgkin lymphoma after allogeneic stem-cell transplantation induces tumorspecific immunity and sustained clinical remission. J Clin Oncol. 2013;31(5):e59-e63.

202. Tsirigotis P, Danylesko I, Gkirkas K, et al. Brentuximab vedotin in combination with or without donor lymphocyte infusion for patients with Hodgkin lymphoma after allogeneic stem cell transplantation. Bone Marrow Transplant. 2016;51(10):1313-1317.

203. Merryman RW, Kim HT, Zinzani PL, et al. Safety and efficacy of allogeneic hematopoietic stem cell transplant after PD-1 blockade in relapsed/refractory lymphoma. Blood. 2017;129(10):1380-1388.

204. Singh AK, Porrata LF, Aljitawi O, et al. Fatal GvHD induced by PD-1 inhibitor pembrolizumab in a patient with Hodgkin's lymphoma. Bone Marrow Transplant. 2016;51(9):1268-1270.
Blood and Lymphatic Cancer: Targets and Therapy

\section{Publish your work in this journal}

Blood and Lymphatic Cancer: Targets and Therapy is an international, peer-reviewed, open access journal focusing on blood and lymphatic cancer research, identification of therapeutic targets and the optimal use of preventative and integrated treatment interventions to achieve improved outcomes, enhanced survival and quality of life for the cancer patient. The manuscript management system is completely online and includes a very quick and fair peer-review system. Visit http://www.dovepress.com/testimonials.php to read real quotes from published authors. 